\title{
Non-Melanoma Skin Cancer in People Living With HIV: From Epidemiology to Clinical Management
}

\author{
Emmanuele Venanzi Rullo ${ }^{1}$, Maria Grazia Maimone ${ }^{1}$, Francesco Fiorica ${ }^{2}$, \\ Manuela Ceccarelli ${ }^{1,3}$, Claudio Guarneri ${ }^{4}$, Massimiliano Berretta ${ }^{1 *}$ and Giuseppe Nunnari ${ }^{1}$ \\ 1 Unit of Infectious Disease, Department of Clinical and Experimental Medicine, University of Messina, Messina, Italy, \\ 2 Department of Radiation Oncology and Nuclear Medicine, State Hospital "Mater Salutis" Azienda Unità Locale Socio \\ Sanitaria (AULSS) 9, Legnago, Italy, ${ }^{3}$ Unit of Infectious Disease, Department of Clinical and Experimental Medicine, University \\ of Catania, Catania, Italy, ${ }^{4}$ Unit of Dermatology, Department of Biomedical and Dental Sciences and Morphofunctional \\ Imaging, University of Messina, Messina, Italy
}

OPEN ACCESS

Edited by: Andrea Ronchi, University of Campania Luigi Vanvitelli,

Reviewed by:

Stefania Napolitano, University of Campania Luigi

Vanvitelli, Italy

Elvira Moscarella,

Università degli Studi della Campania

Luigi Vanvitelli, Italy

*Correspondence:

Massimiliano Berretta massimiliano.berretta@unime.it

Specialty section: This article was submitted to Skin Cancer,

a section of the journal

Frontiers in Oncology

Received: 01 April 2021

Accepted: 07 July 2021

Published: 04 August 2021

Citation:

Venanzi Rullo E, Maimone MG, Fiorica F, Ceccarelli M, Guarneri C, Berretta M and Nunnari G (2021) Non-Melanoma Skin Cancer in People Living With HIV: From Epidemiology to Clinical Management.

Front. Oncol. 11:689789. doi: 10.3389/fonc.2021.689789
Skin cancers represent the most common human tumors with a worldwide increasing incidence. They can be divided into melanoma and non-melanoma skin cancers (NMSCs). NMSCs include mainly squamous cell (SCC) and basal cell carcinoma (BCC) with the latest representing the $80 \%$ of the diagnosed NMSCs. The pathogenesis of NMSCs is clearly multifactorial. A growing body of literature underlies a crucial correlation between skin cancer, chronic inflammation and immunodeficiency. Intensity and duration of immunodeficiency plays an important role. In immunocompromised patients the incidence of more malignant forms or the development of multiple tumors seems to be higher than among immunocompetent patients. With regards to people living with HIV $(P L W H)$, since the advent of combined antiretroviral therapy (CART), the incidence of nonAIDS-defining cancers (NADCs), such as NMSCs, have been increasing and now these neoplasms represent a leading cause of illness in this particular population. PLWH with NMSCs tend to be younger, to have a higher risk of local recurrence and to have an overall poorer outcome. NMSCs show an indolent clinical course if diagnosed and treated in an early stage. BCC rarely metastasizes, while SCC presents a $4 \%$ annual incidence of metastasis. Nevertheless, metastatic forms lead to poor patient outcome. NMSCs are often treated with full thickness treatments (surgical excision, Mohs micro-graphic surgery and radiotherapy) or superficial ablative techniques (such as cryotherapy, electrodesiccation and curettage). Advances in genetic landscape understanding of NMSCs have favored the establishment of novel therapeutic strategies. Concerning the therapeutic evaluation of PLWH, it's mandatory to evaluate the risk of interactions between CART and other treatments, particularly antiblastic chemotherapy, targeted therapy and immunotherapy. Development of further treatment options for NMSCs in PLWH seems needed. We reviewed the literature after searching for clinical trials, case series, clinical cases and available databases in Embase and Pubmed. We review the incidence of NMSCs among PLWH, focusing our attention on any differences in 
clinicopathological features of BCC and SCC between PLWH and HIV negative persons, as well as on any differences in efficacy and safety of treatments and response to immunomodulators and finally on any differences in rates of metastatic disease and outcomes.

Keywords: human immunodeficiency virus, non-melanoma skin cancer, basal cell cancer, squamous cell cancer, immunedeficiency, review (article)

\section{INTRODUCTION}

The natural history of HIV has been significantly modified by the advent of combined antiretroviral therapy (cART) that has prolonged life expectancy and reduced mortality and morbidity of people living with HIV (PLWH). Even if highly active, cART cannot cure HIV and so it is a lifelong therapy because of a hidden, even though active, reservoir $(1,2)$ that is able to escape the treatment. Over the past twenty years, many important factors, as increased age of PLWH and (3) coinfection with oncogenic viruses have promoted the emergence of other malignant neoplasms that collectively are classified as nonAIDS-defining cancers (NADCs) and that, over the years, overtook the incidence of AIDS-defining cancers in PLWH (4-14).

Non-melanoma skin cancers (NMSCs) include primarily basal cell (BCC) and squamous cell carcinoma (SCC). They represent the most frequent malignant neoplasms in the white population, with a worldwide increasing incidence (15). NMSCs develop from epidermal cells and their incidence increases in older age. The pathogenesis is multifactorial: chronic sun exposure is the main environmental risk factor. Other risk factors include increased longevity, genetic mutations, immunodeficiency, concurrent disease and dedicated therapy (i.e., psoriasis) (16). In immunocompromised patients, such as HIV positive patients, the incidence of more malignant form or the development of multiple tumors seems to be higher than among immunocompetent people. In PLWH these malignancies are often more aggressive compared with the general population and they need multidisciplinary assistance (17-26).

The purpose of this review is to describe the incidence of NMSCs among PLWH, focusing on any difference in clinicopathologic features of BCC and SCC between PLWH and HIV negative persons, as well as on any difference in efficacy and safety of treatments and response to immunomodulators, and finally any differences in rates of metastatic disease and outcomes.

\section{MATERIALS AND METHODS}

A systematic search of the EMBASE and Medline databases was performed to identify potentially relevant papers reporting original research on NMSCs in PLWH. This research was performed from inception to 3 March 2021, and it was restricted to humans. Clinical trials, prospective and retrospective studies, case series, case control studies and metanalysis concerning the topic of NMSCs in PLWH published in English, Spanish and Italian with available abstracts, were selected if they addressed one or more of the following topics: BCC, SCC, basal cell carcinoma, squamous cell carcinoma, HIV. The following search strings were used: "BCC OR basal cell carcinoma AND HIV", "SCC OR squamous cell carcinoma AND HIV". Reviews, expert opinions, book chapters and articles lacking original data were excluded. The title and abstract of all articles retrieved were check by two reviews (EVR and MGM) who selected relevant articles for full text evaluation according to predetermined criteria. Discrepancies were resulted by a third reviewer (MB). Studies were compared by title and abstracts to eliminate duplicates. A Preferred Reporting Items for Systematic Reviews and Meta-Analyses (PRISMA) flow diagram (Downloaded 03 March 2021, http://prisma-statement.org/ PRISMAStatement/FlowDiagram.aspx.) was set to illustrate the review process (Supplementary Materials). We summarized the review according to PRISMA guidelines, represented below).

\section{EPIDEMIOLOGICAL PROFILE OF NMSCs}

Non-melanoma skin cancers (NMSCs) are the most frequent neoplasms in Caucasians and their incidence is increasing worldwide, with $80 \%$ diagnosed as BCC followed by SCC being both more common than melanomas (27). They are much common in white population than in skin color people. Their incidence results 18-20 times higher than that of melanoma (28). Epidemiologic studies highlight that the worldwide incidence varies widely. In fact, BCC has higher incidence in equatorial latitudes and lower in polar latitudes. Australia is the country with highest incidence of BCC, followed by the US and Europe, although the real incidence is globally underestimated (29). In Australia the rate for BCC is more than 1,000 per 100,000 person-years $(2,448 / 100.000)$, followed by Europe (91 in women and 129 in men per 100,000 person-years) and the US (450 per 100,000 person-years). Cutaneous SCC is the most common skin cancer, behind BCC, and it represents approximately 20 percent of NMSCs (30). Its incidence increases more quickly with age than BCC. In PLWH cancer is becoming a growing problem representing now the first cause of death. It is clear that cancer risk is higher in PLWH in comparison with the general population (31), less clear are the reasons behind it. The advent of cART has improved the morbidity and mortality of PLWH, prolonging their life expectancy (32). A large body of literature has highlighted that HIV infection is associated to an increased risk of several 
different type of cancers besides NMSCs, such as lung cancer, cancer of the colon and rectum, Hodgkin disease, hepato-cellular carcinoma, head and neck SCC (HNSCC), conjunctival SCC and anogenital SCC $(10,17,19,20,33,34)$. BCC in PLWH show a 1.8-fold increased risk in comparison with HIV negative people (35), but it could be better in patients that have a good control of the infection. The occurrence of multiple BCC in PLWH without additional risk factors is uncommon. In HIV positive patients BCC is essentially more frequent than SCC (36) and ratios around 4:1 of BCC versus SCC have been found, similar to the general population (4:1) (33). In a retrospective cohort that studied $36821 \mathrm{HIV}$ negative and $6560 \mathrm{HIV}$ positive patients it has been shown an increased risk for BCC among PLWH. In fact, in this Californian cohort, the risk of developing a BCC was about twice as likely in non-Hispanic white PLWH than in the same HIV negative population. So that, it has been denoted that patients with HIV showed a meaningful tendency to develop BCC as HIV negative persons (37). Regarding HNSCCs, they are a heterogeneous group of cancers occurring in various anatomic sites, including scalp, oral cavity, lips, oropharynx, nasopharynx and larynx.

\section{Focus on SCC of the Scalp}

SCC of the scalp represents approximately $16 \%$ of scalp cancers (38), with a mean age of 65 years at diagnosis. It has a positive correlation with advanced age.

Known risk factors for developing SCC of the scalp are older age, history of ionizing radiation chronic scarring, androgenetic alopecia, ultraviolet light exposure, actinic damage.

Immunosuppression is a crucial risk factor for all SCCs (39) that represent the most common cancer in immunosuppressed patients, with greater potential for tumor growth, cell differentiation, and aggressiveness. Furthermore, SCC may show a higher risk of metastatic disease and death in immunocompromised patients compared with immunocompetent individuals (40).

A retrospective study showed that twenty out of fifty-tree immunocompromised patients affected by cutaneous SCC of the scalp had bone invasion, that is associated with poor prognosis (41).

The aggressive behavior of SCC on the scalp in immunosuppressed patients has been described by Lang et al. (42). It is recommendable to manage scalp tumors aggressively and appropriately because they are associated with important morbidity and mortality. So that, it is essential to monitor for bone invasion, recurrence, perineural invasion and metastasis. A better knowledge of the mechanisms of recurrency could be helpful to prevent morbidity and mortality in this specific group of patients. Concerning the clinical presentation of SCC of the scalp in HIV positive patients, Ferreira CP et al. have described a case report of a sixty years-old male, white, and HIV positive in use of zidovudine, lamivudine and efavirenz, presenting tumor located in scalp, progressing with rapid growth for one year. The histopathological examination revealed a diagnosis of well differentiated SCC. Immuno-virological profile revealed CD4: 62 cells $/ \mathrm{mm}^{3}$; CD8: 1,654 cells $/ \mathrm{mm}^{3}$; viral load: 91,000 copies. CT brain scan revealed cerebral foci of calcification in the suprasellar region as well as in basal ganglia on the left, with a diameter of $15 \mathrm{~mm}$ and invasion to the skull along the interparietal suture. The patient had subsequent pneumonia that was the final cause of death. Fortunately, SCC is often diagnosed before the invasion to the skull because of its slow progression. Rarely, SCC can extend to the brain and invade, in late stages, the skull and the dura mater. When this event occurs, patients may present neurological symptoms (43). Because of the anatomical profile of the scalp region, margin excision is not always possible. Preoperative imaging is essential to define the proper extent of invasion and choose the correct treatment strategy. The treatment of SCC in advanced stages is challenging starting from the multidisciplinary surgical approach needed for a proper excision. Further studied are required for advanced disease.

\section{RISK FACTORS AND PATHOGENESIS}

Among immunocompetent light-skin color people, the development of NMSCs is favored mainly by chronic sun exposure and increasing age. There are important phenotypic characteristics, such as fair skin type, light-colored eyes, red hair, northern European origin and childhood freckling (44) that influence vulnerability to solar radiation. The frequency and intensity of sun exposure are also important.

Other environmental risk factors that contribute an increased risk for NMSCs include older age, family history of skin cancer, immunodeficiency (45), previous radiotherapy, long-term immunosuppressive treatment, genetic syndromes and chronic, mostly occupational, exposure to arsenic (46).Moreover, several observational studies have documented a correlation between use of photosensitizing molecules and increased risk for BCC (47).

\section{The Genetic Landscape of NMSCs}

Mutations of numerous tumor suppressor genes and protooncogenes play a key role as drivers in BCC formation (48). In almost $90 \%$ of cases, mutations that activate the Hedgehog pathway $(\mathrm{HH})$ play an established role in the development of BCC (48), while SCC is characterized by a high neoantigen burden (37). In about $50 \%$ of BCC cases, TP53 tumor-suppressor gene mutations are caused by UV radiation. TP53 encodes the P53 protein involved in maintain genomic stability by regulating the cell cycle, inducing apoptosis and activating DNA repair. Furthermore, mutations identified in PTCH1 and TP53 are socalled UV signature mutations, because in most cases they are consistent with ultraviolet radiation-induced mutagenesis.

Among genetic syndromes that may increase the risk for the development of BCC, we should keep on mind Gorlin-Goltz syndrome, also called Nevoid BCC syndrome, an autosomal dominant disease with multiple lesions of the skin, pits of the palm and developmental defects (49).

Moreover, oculocutaneous albinisms and xeroderma pigmentosum, which are known as genetic diseases with deficiencies of the protective mechanisms against UVR, are characterized by multiple and early BCCs (50). 
Concerning the genetic landscape of SCC, multiple studies have shown that genes altered by UVR exposition are TP53, CDKN2A, NOTCH1, NOTCH2 and p16 suppressor gene. Moreover, mutations in DNA repair pathways include missense mutations in ATR, PIK3CA, ERRB4 and NF1 (51). In addition, association between SCC and genetic syndromes as oculocutaneous albinism, xeroderma pigmentosum, Fanconi anemia, epidermolysis bullosa and Lynch syndrome has been found (52).

\section{A Brief Focus on Possible Links Between the Innate Immune System and NMSCs}

A large body of studies highlights that innate immunity play a key role in NMSCs development and progression. Their role has attracted increasing attention recently. As well known, the innate immune system cells can recognize numerous exogenous ligands, such as infectious agents, through various mechanisms. The most important genetic pathway networks involve a crucial group of receptors, called toll-like receptors (TLRs) (53). They are a family of ten transmembrane glycoproteins that directly recognize a wide spectrum of pathogen-associated molecular patterns (PAMPs) and damage-associated molecular patterns (DAMPs), against which they activate the innate immune response and initiate the adaptive immune response (54).

TLRs play a crucial role in the activation of innate immunity, promoting cancer progression; therefore, their activation induces genes that encode for numerous inflammatory cytokines, such as tumor necrosis factor- $\alpha$ (TNF- $\alpha$ ), INF-1, IL-6, IL-1, granulocyte-colony stimulating factor and different chemokines, including CCL2 and CXCL10 $(54,55)$.

It has been observed that some TLRs are involved in the pathogenesis of numerous inflammatory and autoimmune skin disorders. Particularly, there is evidence that Imiquimod, a synthetic agonist of TLR-7, presents high efficacy for treatment of superficial BCC, with a cure rate ranging from 43-94\% (56).

The high efficacy of this TLR-7 agonist against superficial $\mathrm{BCC}$, suggests a possible role of this receptor in the pathogenesis of BCC. As a possible consequence, polymorphisms of this receptor could change host immune responses, determining a different susceptibility to BCC and others cancers and autoimmune diseases (57).

A recent case control study performed by Russo et al. (58) highlights the possible association between the susceptibility to BCC and a functional single-nucleotide polymorphism within the promoter of TLR-7 gene (SNP rs 179008/Gln11Leu).

Further genetic research of this receptor and its ligands are needed to improve the knowledge of the pathogenesis of BCC and other UV-related skin cancers.

An increasing body of evidence shows that BCC is an immunogenic tumor (59). Several immune-related markers have been implicated in BCC pathogenesis. IL-23/Th17 related cytokines, as $17,23,22$, play a significant role in cutaneous inflammatory diseases, but their involvement in skin carcinogenesis is controversial and is poorly investigated in BCC. A recent study of Pellegrini $\mathrm{C}$ et al. has highlighted the role of INF- $\gamma$ in BCC pathogenesis, supporting the involvement of IL-23/Th 17 related cytokines. Particularly, it has observed that BCC is characterized by higher levels of IFN- $\gamma$, IL-17, IL-22 and IL-23. Their expression could be correlated to the severity of the inflammatory infiltrate.

Concerning cSCCs, as well known, they are characterized by high mutational burden and cellular heterogeneity (60).

The role of immunosuppression in cSCC risk is supported by higher incidence among recipients of solid organ transplants and PLWH $(37,61)$, suggesting that this tumor type has enhanced many elements of innate immune response compared to normal skin. The immune system plays complex roles over the entire process of cancer initiation, promotion and progression.

Presentation of tumor antigens to CD8+ cytotoxic T cells and CD4+ helper T cells by HLA class I and class II molecules, respectively, is a key component of this process. The immune response is modulated by human leukocyte antigens (HLAs), which are encoded by a cluster of highly polymorphic genes located on chromosome 6 . At the same time, inflammation can facilitate cell transformation by providing pro-tumorigenic cytokines and growth factors to tumor cells and forming an immune suppressive microenvironment within the tumor, which ultimately lead to immune escape and clinical manifestation of the tumors (62). A growing body of literature shows that variation in the expression pattern of these proteins, involved in the presentation of tumor antigens to T lymphocytes, has been implicated in multiple cancers by influencing host defenses against tumorigenesis. The exact mechanisms underlying these associations need to be elucidated. The strongest association between amino acid changes and cSCC risk was found for codon 26 of HLA-DRB1. However, the true functional impact of the phenylalanine to leucine change remains to be elucidated. The identification of specific amino acid changes in the HLA class II genes, if confirmed, helps provide mechanistic clues to the relationship between HLA-mediated immune response and cSCC tumorigenesis. Future studies that examine the mechanism underlying the association between HLA class II and $\mathrm{CSCC}$ risk need to be performed. The immune system impacts cSCC susceptibility and pathogenesis, as evidenced by the substantially higher incidence of cSCC in immunocompromised patients. Furthermore, susceptibility to the effects of UVR is known to be genetically determined (63). Variations in immunological makeup of human hosts may influence their ability to recruit immune responses needed to prevent cSCC development. Particular HLA genetic variants are associated with $\mathrm{CSCC}$ in immunocompetent and immunosuppressed patients, with more evidence for class I HLA-cSCC associations in immunosuppressed patients than in immunocompetent patients. Class I HLA could play a more important role in cSCC in immunosuppressed patients because HPV may be a co-factor in tumorigenesis- class I HLA proteins present intracellular peptide antigens, including viral proteins degraded into peptides. Further researches of tumor antigens involved in CSCC pathogenesis are needed, to better understand cSCC pathogenesis from an immunological point of view, and try to provide an effective prevention and treatment of cSCC (64). 


\section{Skin Cancer, Chronic Inflammation, and Immunodeficiency: A Mènage A Tròis}

Cutaneous manifestations often may reveal themselves important clinical clues of many diseases in general, including neoplastic skin diseases, that brings the patient to the physician.

The cutaneous immune system is usually linked to defense against pathogens and external agents; it can also promote the neoplastic process and tumor progression through inflammation.

As known, inflammation plays a key role in oncogenesis (Figure 1). Different kinds of cancers arise from infections or chronic inflammation that represent the main promoters of chronic activation of immune system. This prolonged immune activation triggers various stages of carcinogenesis.

As known, immunodepression HIV-related determines an increased risk of tumors (65).

Moreover, HIV shows a tropism for cells of the human immune system, such as macrophages, dendritic cells and Tlymphocytes. HIV infection, through different processes, leads to the reduction of CD4 T-cells to a critical level. Below this level, cell-mediated immunity is lost, and this event allows the rise of opportunistic infections and AIDS development.

Regarding the mechanisms by which HIV virus induced lytic activities, Pope et al. (66) suggested that direct contact between CD4 T cells and HIV pulsed dendritic antigen-presenting cells triggers replication of the virus, leading to a death to both cell types. Furthermore, delayed-type hypersensitivity tests usually have been used as monitors for the progression of the infection, because of the compromise of cutaneous immune system is crucial (67). When CD4 and antigen-presenting cells count decrease meaningfully, skin becomes susceptible to numerous opportunistic infections and neoplastic diseases. In addition, HIV virus seems to activate proto-oncogenes (68), cause alterations in cell cycle regulation and inhibit tumor suppressor genes including p53 (69). Moreover, HIV could determine microsatellite gene instability and genetic alterations, promoting formation of different cancers, including NMSCs (70) (Figure 2).

Finally, HIV infection may booster pro-angiogenesis signaling that could lead to endothelial abnormalities. These alterations could promote tumor growth and metastasis (71).

Cutaneous malignancies are the majority of cancers among HIV positive patients (72) and NMSCs are now the most frequent cutaneous malignancies among PLWH. The main risk factors for NMSCs are similar to HIV negative people. Accumulate worldwide studies have shown that NMSCs are usually more aggressive in immunocompromised patients, as evidenced by an increased risk of metastatic disease and mortality in comparison with immunocompetent individuals (73). Frequent opportunistic infections represent also important risk factors for NMSCs (74).

In a study by BURGI et al. (72), cART therapy was associated with lower rates of NMSCs, whereas the standardized incidence ratio (SIR) for NMSCs was reported not to be decreased in the post-cART era among patients recorded in the Swiss cohort study (36). Moreover, a study by Silverberg et al. has suggested that the cART use is associated with decreased risk. Generally, PLWH with BCC and SCC tend to be younger, to have an increased rate of recurrence and they seem to have an overall poorer outcome (75). They often present with more advanced stages of the disease, with a greater degree of infiltrative disease and poorer outcomes (76). In PLWH possible etiologies of NMSCs include the HIV virus, coinfection with oncogenic viruses, such us hepatitis $B$ virus (HBV) (77), hepatitis $C$ virus (HCV) (78), human papilloma virus (HPV) and Epstein Barr virus (EBV) (79), cART agents and tobacco exposure. HPV skin infections are common but the exact correlation between HPV infection and the developing of cutaneous SCC remains still less clear (80). Multiple studies have reported indirect evidence supporting an etiologic relationship (81).

Skin cancer, chronic inflammation and immunodeficiency: a menage a trois

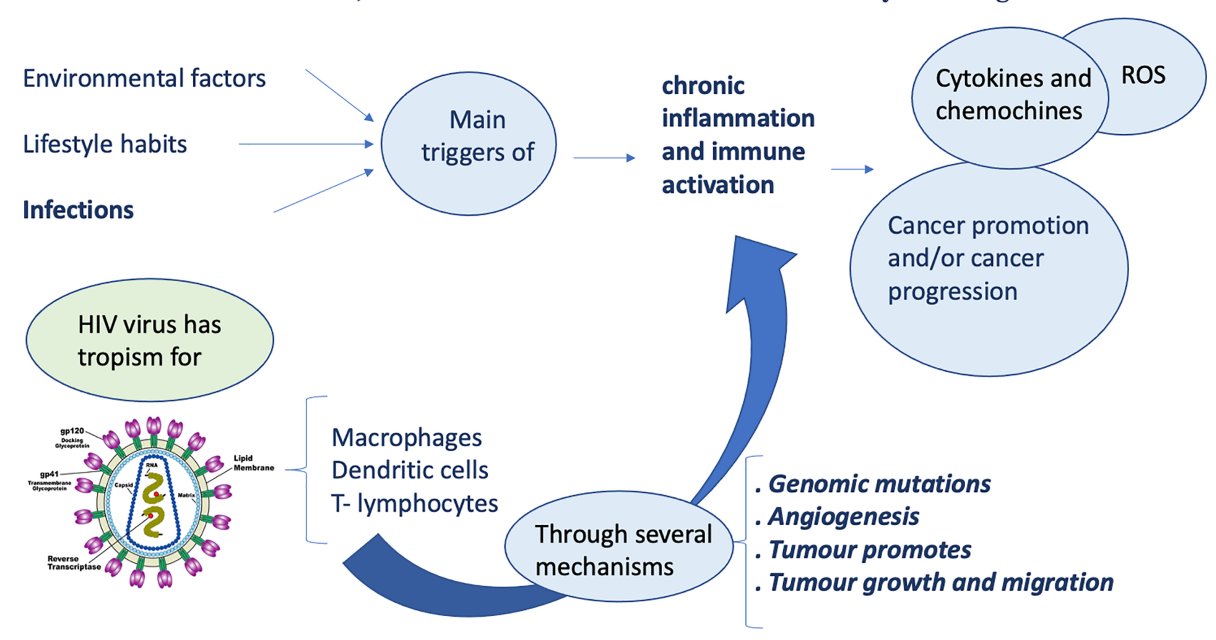

FIGURE 1 | Chronic inflammation and immune activation: a delicate balance. 


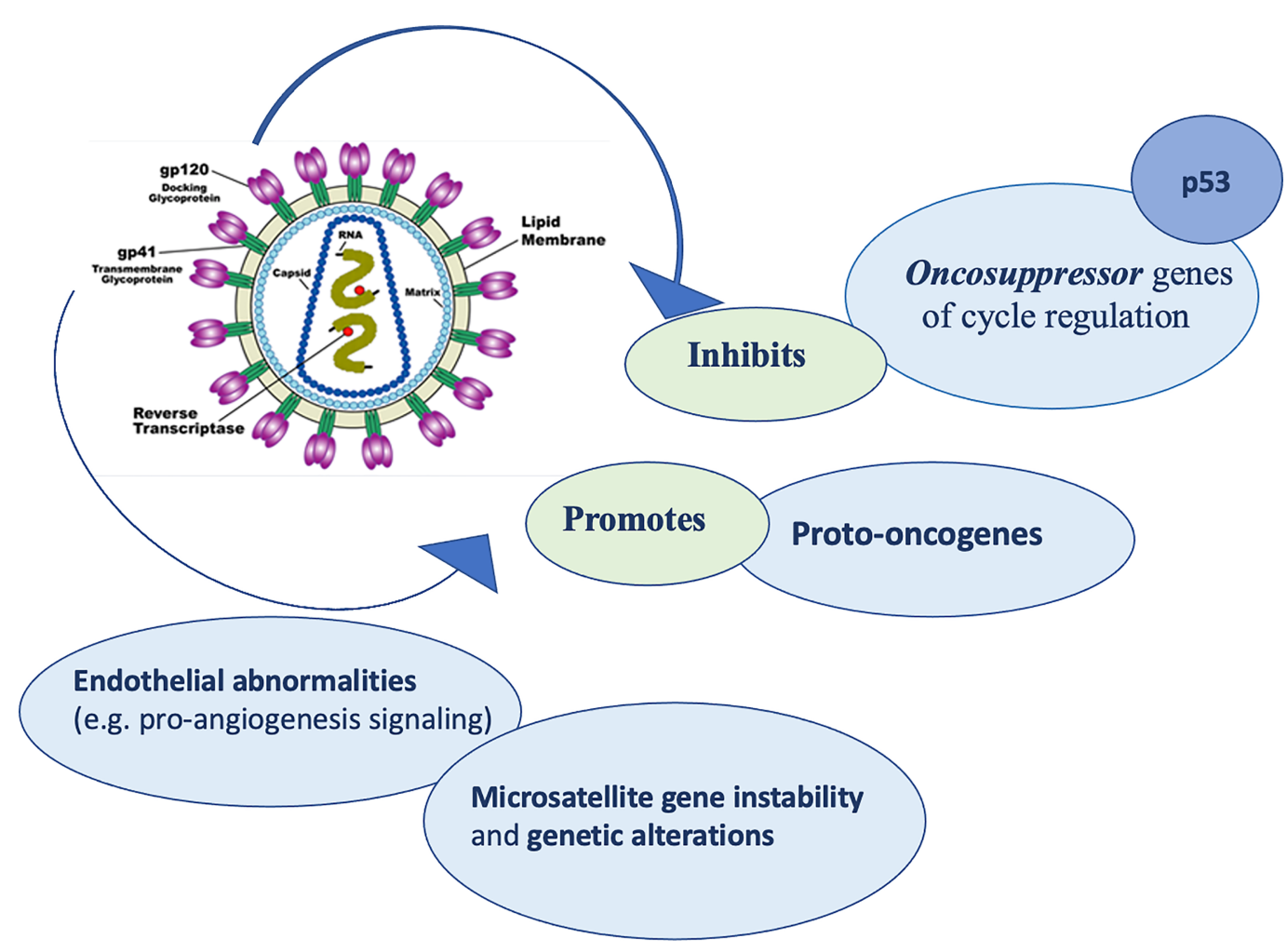

FIGURE 2 | The pathogenetic role of HIV.

\section{Exploring the Link Between Viral- Immunologic Profile of HIV Positive Patients and Risk of NMSCs}

Current knowledge of the correlation between viralimmunologic profile of HIV positive patients and NMSCs is evolving. A peculiar correlation between decreased immunesurveillance and carcinogenic virus co-infections might favor oncogenesis, increasing the risk of developing tumors in these subjects (see Figure 3).

CD4 cell count is one of the main investigations in the clinical evaluation and management of HIV-infected patients and the skin is richly endowed with these cells. Immunocompetent and PLWH seemed to share the same genetic and environmental factors that lead to the formation of NMSC. Immunosuppression can increase risk to develop NMSCs, mostly SCC (82). An increased rate of neoplasms could be likely to explained by the progressive decline and dysfunction of $\mathrm{T}$ cells associated with HIV infection.

HIV infection causes reduced activation of both CD4 and CD8 cells and an increased synthesis of TH2 cytokine subsets. This event leads to cell-mediated immunity deficiency and accumulation of genetic mutations. HIV produces specific proteins, such as nef and tat, that alter MHC signaling and chemokine production (83).

How HIV infection could be the cause of oncogenesis it is complicated to demonstrate, especially because it seems not to be correlated with the overall immune status (CD4 counts and viral load) (84). A meta-analysis of Grulich et al. (85) have showed that immune deficiency caused an increased risk of cancer. HIV positive patients, with CD4 counts $<200 /$ microL and high viral loads $>10,000$ copies $/ \mathrm{mL}$, have a twofold increased risk of developing a primary SCC. The association between level of immunodeficiency and risk of NMSCs is less clear, with a correlation with only SCC having been observed (37). Recently, it has been demonstrated an increased rate of NMSCs among PLWH (37). In 2017, Asgari et al. reported that non-Hispanic white PLWH had a greater risk of developing a new subsequent SCC and that this risk is correlated with lower CD4 counts and higher viral loads. The study failed to demonstrate the same for BCC. In PLWH a 15\% increased risk of NMSC has been demonstrated. In particular, the possibility of a subsequent NMSC seemed to be correlated with profound immunecompromission (CD4 <200) (86).

These findings suggest that HIV-related immunodeficiency can determine an increased risk of NMSC overall and SCC in particular. In addition, the HIV viral load, often influenced by antiretroviral therapy adherence, was associated with subsequent primary SCC (hazard ratio of 2.28 with a VL above 10,000 copies/mL) but not for BCC (86). However, this study presents some limitations. The confidence intervals surrounding their HRs are not wide, suggesting that their findings were sufficiently powered. PLWH, especially those with poor immune control, 


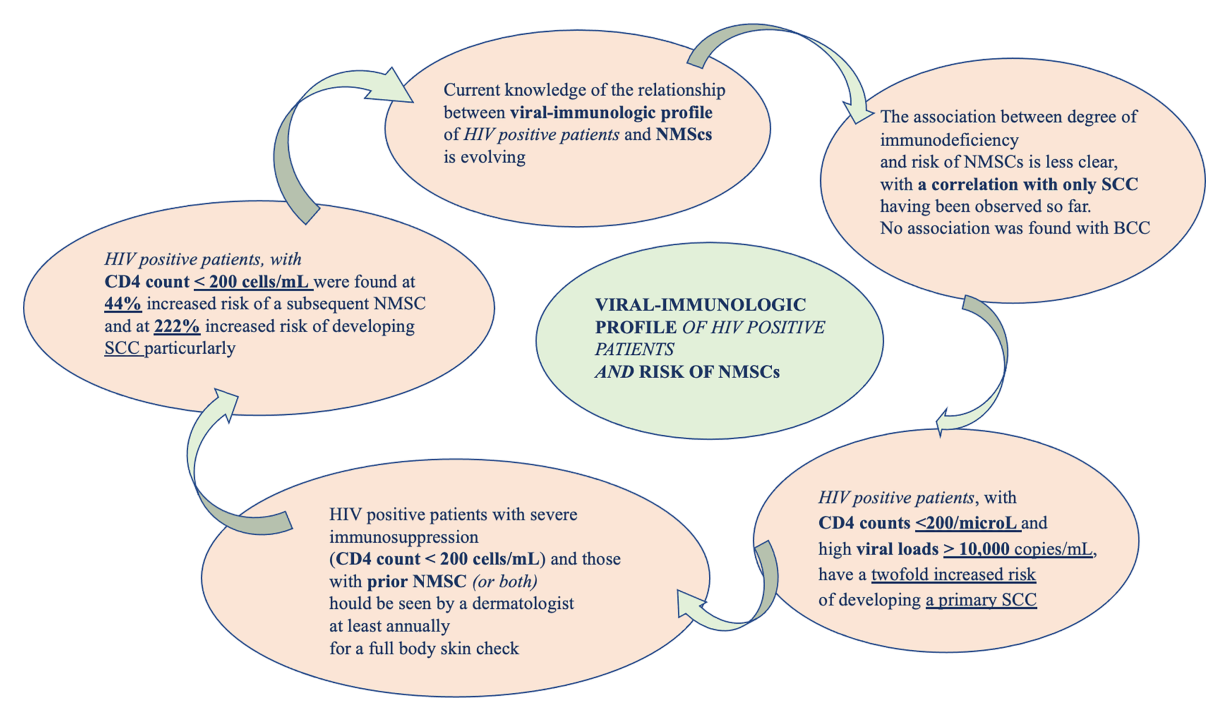

FIGURE 3 | The exploration of a bond between NMSCs and immuno-viral profile of PLWH.

could potentially benefit from targeted monitoring for SCC. In these cases, Sarah J Coates et al. recommended that patients with prior NMSC should undergo a careful dermatologic evaluation at least every year (87).

\section{CLINICAL PRESENTATION AND DIAGNOSIS}

BCC derives from the deepest cell layer of the epidermis, the basal layer of keratinocytes. Its clinical presentation is notably heterogeneous. It usually appears as a waxy, translucent, or pearly lesion that often shows a central ulceration and a raised pale border. Telangiectasias are frequent and they often bleed. Moreover, they lead to friability and poor healing. The lesion can appear atrophic and the borders can be indistinct (88). Approximately, in 9 cases out of 10, BCC arises on the head and in 7 cases out of 10 on the trunk and extremities (89). Although BCC shows minimal metastatic potential $(<0,1 \%)$, local tissue effects can be destructive and disfiguring (88). Diagnosis is primarily histologically. The main histologic patterns are: nodular, superficial, morpheaform/infiltrative, basosquamous, micronodular and pigmented. Morpheaform/ infiltrative, micronodular and basosquamous are considered more "aggressive growth" subtypes of BCC. Moreover, some lesions present a mixed histology.

SCC arises from atypical proliferation of keratinizing cells of the epidermis or its appendages. It often develops from actinic keratosis and Bowen's disease (SCC in situ) which are considered precancerous lesions. It can also grow de novo or on irradiated skin regions, or on chronic inflammatory skin disorders. In contrast to BCC which rarely metastasizes, SCC can metastasize initially to regional lymph-nodes and subsequently to distant regions (90). Typical clinical aspect of SCC is a raised pink papule or plaque, sometimes with scaling or an ulcerated center. The borders often are irregular and bleed easily. During the first years of follow-up, it seems to be less frequent that AKs turns into invasive SCC. When SCC arises from actinic keratosis, it appears scaly, but it tends to grow thicker, and a pink macular area develops into an erythematous raised base. Because SCC may seem quite similar to actinic keratosis, only skin biopsy accurately identifies significant cytologic atypia and invasion of SCC (89). Clinical appearance of SCC is extremely heterogeneous, and it depends also on the anatomical region and subtype. The diagnosis of SCC is primarily histologically. In all clinically suspicious lesions, a skin incisional biopsy or excision, need for a histologic confirmation, should be performed initially, depending on the size of the cancer and treatment approach (see Figure 4). It is possible to perform an incisional (punch or shave biopsy) or an excisional biopsy of the whole lesion. Moreover, in rare cases of uncertain diagnosis, immunohistochemical markers of differentiation, such as cytokeratin or molecular biological markers can be applied (50).

Generally, PLWH with SCC and BCC present identically to immunocompetent individuals (91). BCC generally appears on the trunk, while SCC on the head and neck regions. Superficial type BCC is the most typical clinical and histologic presentation, which tends to be multiple, involving the trunk. Generally, in PLWH malignant cancers show a more aggressive phenotype and poorer survival rates in comparison with immunocompetent persons. NADCs show often earlier age at onset, higher tumor degree, more aggressive clinical course and/or more advanced stage at presentation, highlighting the need for prompt and aggressive treatment. More aggressive clinical course has been correlated with multiple factors, such as anatomic site, size at onset, growth rate, histologic features and recurrence after treatment (92). A substantial body of evidence on metastatic 


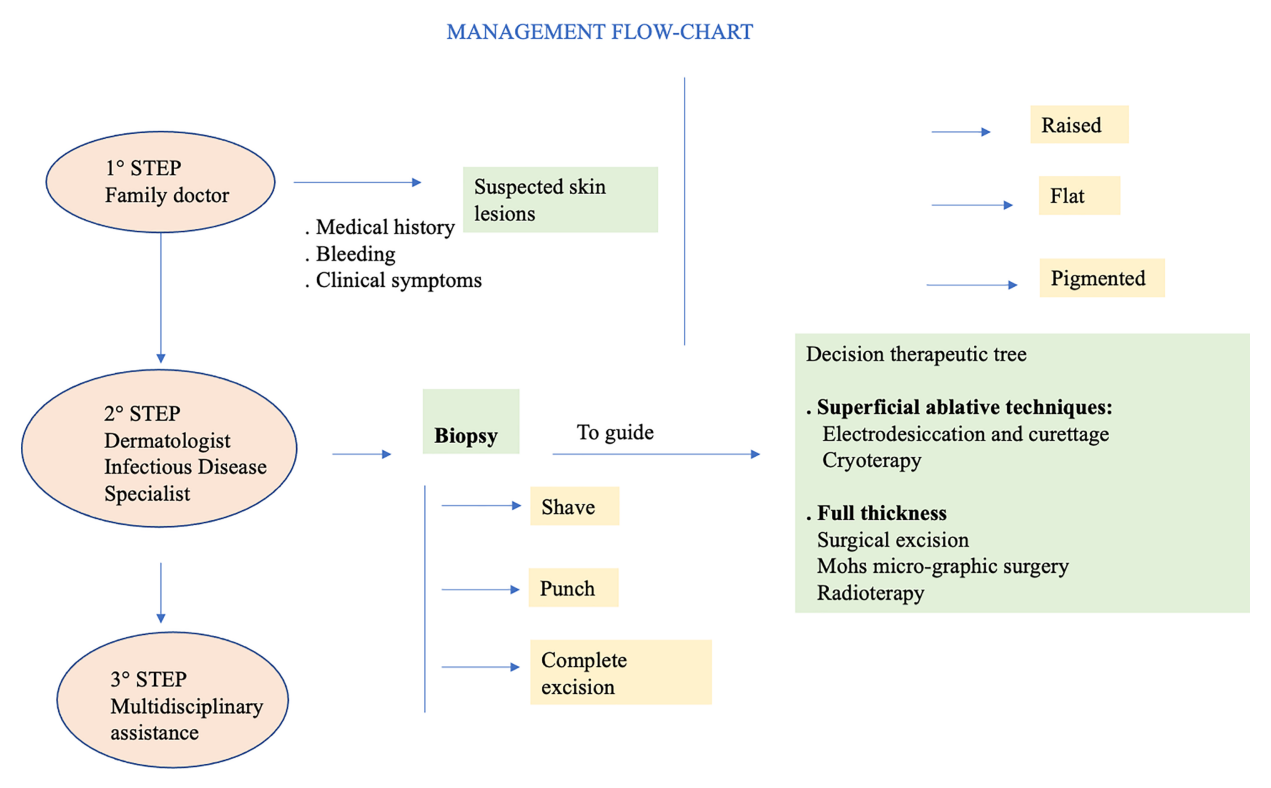

FIGURE 4 | Diagnostic Management flow chart of NMSCs.

SCC highlights that head and neck are primary sites; particularly the temporal and zygomatic regions seem to have a clear tendency for metastasis, maybe because of rich and direct lymphatic drain-age to the parotid gland (93).

Nguyen et all. have demonstrated that PLWH can develop rapidly growing SCC at a young age, with a high risk of local recurrence and metastasis. Management of high-risk SCC should be aggressive and not palliative in PLWH (92). However, cART has certain improved the life quality of PLWH and their outcome that appears more similar as in the general population. Several worldwide studies have highlight that in PLWH, NMSCs are usually characterized by a more aggressive clinical course, higher cancer grade, advanced stages at cancer diagnosis and shorter survival compared with HIV negative individuals (74). SCC seem to be more dangerous in the context of HIV disease. R. N. Motta et al. have described the case of a 59-year-old male patient with advanced HIV infection who presented with a highly aggressive SCC lesion scalp area with destruction of the underlying parietal bone and fulminant clinical progression (94).

Nguyen et al. (92) have described ten cases of aggressive SCC. They recorded 41 different SCC lesions: $75 \%$ in head and neck, $7 \%$ in the trunk and $8 \%$ in extremities.

based on rapid growth rate, a diameter of over $1.5 \mathrm{~cm}$, a history of recurrence and/or evidence of metastasis. A total of 41 SCC lesions were recorded from 10 patients. The head and neck were the most frequently involved regions (31 lesions), followed by the trunk ( 7 lesions) and extremities (1 lesion). The article stated that those patients initially treated with radiation therapy and surgery combined as well as those treated with radical neck dissection had the best outcomes (92). This paper suggests that high-risk SCC should be treated aggressively and not palliatively in patients infected with HIV.

\section{FROM PREVENTION TO THERAPY}

Skin cancer can be avoided by following simple prevention rules (95). Primary prevention is of utmost importance. In particular, sun exposure should be reduced and totally avoided when at its peak during the day, and intensive tanning discouraged. Secondary prevention should be aimed to reduce morbidity and mortality, mainly through early detection of skin cancer, as close clinical evaluation of the arms, face and upper chest can uncover many lesions. In PLWH it is vital a careful evaluation with early biopsy of suspicious lesions. Precancerous lesions should be undergone an early diagnosis to prevent the development of invasive SCC. When cycle of therapy is concluded, patients should undergo a regular follow-up with evaluation of local recurrence or nodal metastasis, particularly for SCC. Other important prevention strategies include smoking cessation and prevention and/or treatment of oncogenic viruses' coinfections, such as $\operatorname{HPV}, \operatorname{HBV}, \operatorname{HCV}(13,26)$. HPV plays an important etiologic role in genital SCC, so that the quadrivalent HPV vaccination has been strongly suggested (96). Generally, cancer therapy is chosen on the basis of location of primary disease, extension and spread and host comorbidities. Moreover, it depends on histology, lesion aspect, size and location, as well as patient compliance. BCC and SCC should be primarily treated with complete surgical excision (97) (see Figure 5).

Management of BCC remains primarily surgical (98), as in immunocompetent people. Management of SCC is influenced by clinical presentation (i.e., palpable lymph nodes) and histopathologic features. Generally, a full skin examination should be performed in all patients, followed by lymph node examination and by surgical and medical management involving a team of experts. It is important to extend the excision at least 


\section{TREATMENT OPTIONS FOR NON MELANOMA SKIN CANCERS}

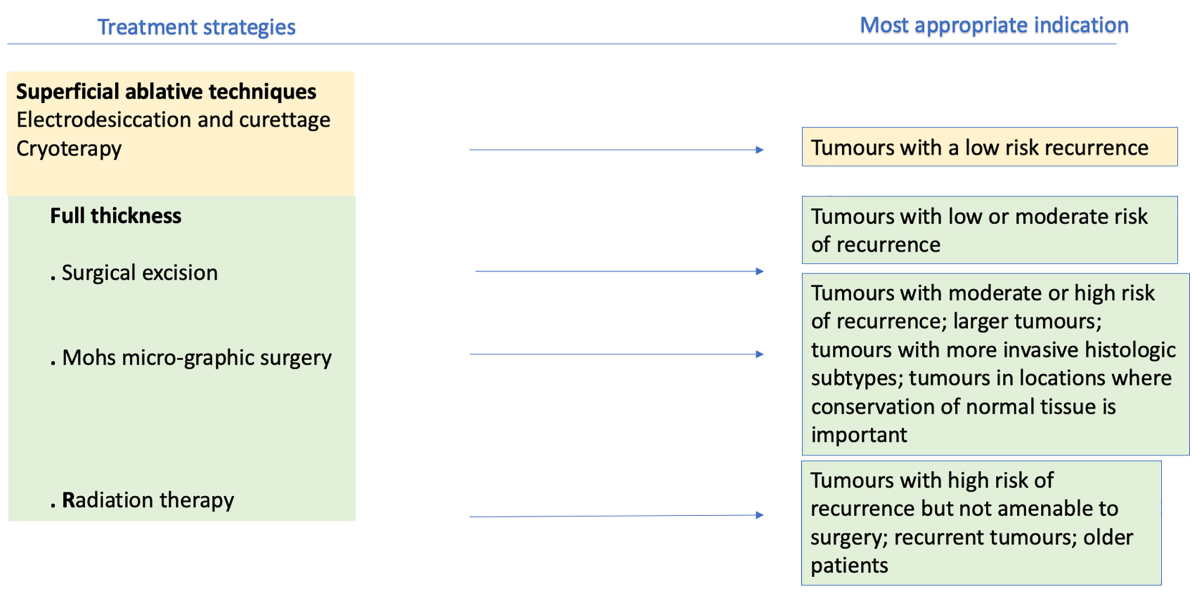

FIGURE 5 | Treatment options for NMSCs.

$6 \mathrm{~mm}$ from the margins independently from the site whenever it is possible (98). Standard treatment should be applied to all PLWH with a newly diagnosed NMSCs (99); however, when combining cART with chemotherapy, potential drug-drug interactions and overlapping toxicities such as nausea and diarrhea, myelosuppression, neuropathies may occur (99). In case of overlapping toxicity occurs, it is recommendable to change cART or the chemotherapy agent rather than stopping the antiretroviral therapy or decreasing the dosage of chemotherapy (99). Many studies suggested that outcomes can be similar in PLWH with a good control of their infection and HIV negative people (100). However, PLWH with advanced disease show a poor tolerance of therapy and they more likely have worse outcomes compared with HIV negative individuals (101). In immunocompromised individual oral retinoids could be effective to reduce cancer load and to partially prevent the occurrence of new lesions. Unfortunately oral retinoids are teratogenic and that represent a limitation in their use (102). Morbidity and mortality of aggressive SCC in PLWH depend on the control of the disease in the early stages (92). People with higher risk cancers should receive loco regional adjunctive radiotherapy or chemotherapy or both and sentinel node procedures. These recommendations apply regardless of CD4 counts. There is no evidence that BCC in PLWH need more aggressive therapy. For example, Wilkins et al. recommend the use of the same treatment protocols for treatment of BCC even if there is no evidence for imiquimod for BCC in PLWH (91). Among factors influencing prognosis, any kind of immunocompromised patient present more rapid growth, an higher risk of local recurrence and metastasis, even 10 times higher (82). Intensity and duration of immunodeficiency plays a great role (103). Immunocompromised patients should be followed-up closely, at least twice a year (50). PLWH can die of a metastatic SCC, so the treatment of SCC in PLWH should never be less aggressive or prompt than the treatment of HIV negative individuals. Concerning metastatic SCC, it is important to keep in mind that late treatment of high-risk SCC could lead to metastatic diseases especially in immunocompromised people. Moreover, perineural invasion is clearly linked to recurrence and higher risk of metastasis. Generally, the most chosen surgical option in these high-risk cases is Mohs surgery. But the presence of perineural invasion requires additional adjuvant therapy (104). Similarly, high-risk SCC in HIV infected patients should be treated initially by ablative therapy with histologic control and, if necessary, adjuvant therapy. A retrospective study of Nguyen has illustrated the potential for rapid growth of SCC in HIV infected people. An initial less aggressive therapeutical approach in PLWH is linked to higher rates of recurrence, metastasis and death. For this reason PLWH with SCC should receive a combination of surgery and radiotherapy or of surgery and radical neck dissection (92). NMSCs are a striking example of immunodeficiency-related neoplasm, and they offer further opportunities for therapeutic and pathogenetic insights. In fact, multiple clinical phenomena highlight the close correlation between immunity and skin cancers.

The main therapeutic techniques, superficial ablative and full thickness, for NMSCs will be broadly reviewed above (see Table 1).

\section{Surgical Excision}

Surgery is the treatment of choice. Depending on the affected area, it can be followed by plastic reconstruction. Moreover, histological examination of the excised tissues allows diagnosis, prognosis and treatment tailoring.

In SCC, surgical excision is immediately followed by histopathological examination of excision margins, which allows to confirm the cancer type and assess the absence of cancer cells from the resection margins. Another procedure to obtain the same result is micrographically controlled surgery 
TABLE 1 | Classification of BCC according to risk for recurrence $(105,106)$.

\begin{tabular}{|c|c|c|}
\hline LOW RISK & INTERMEDIATE RISK & HIGH RISK \\
\hline Superficial primary BCC & Superficial recurrent BCC & Clinical forms: Morpheaform or ill-defined \\
\hline Nodular primary BCC when: & Nodular primary BCC when: & Nodular primary BCC when: \\
\hline$<1 \mathrm{~cm}$ in intermediate risk area & $<1 \mathrm{~cm}$ in high-risk area & $>1 \mathrm{~cm}$ in high-risk area \\
\hline \multirow[t]{2}{*}{$<2 \mathrm{~cm}$ in low-risk area } & $>1 \mathrm{~cm}$ in intermediate risk area & \\
\hline & $>2 \mathrm{~cm}$ in low-risk area & \\
\hline \multirow[t]{3}{*}{ Pinkus tumor BCC } & & Histological forms: \\
\hline & & Aggressive \\
\hline & & Recurrent forms \\
\hline
\end{tabular}

(MCS). For low-risk NMSCs limited to dermis, traditional excision preferred (89). Aesthetically, excision offers better results than ablative techniques. Moreover, it offers the advantage of obtaining specimens for histologic examination. With surgery, cure rates are higher than $90 \%$. It is neither recommended, nor cost-effective, storing frozen sections of tumor margins of every suspected NMSC. MMS is applied for recurrent tumors, tumors in high-risk areas, tumors $\geq 2 \mathrm{~cm}$, recurrent tumors, tumors which margins are not clear and tumors in cosmetically sensitive areas (107). Wide removals should be done when margins are smaller than the recommended safety margins due to the tissue shrinkage, while re-excision should be done for operable cases in the event of positive margins (108). In the context of high-risk SCC, usefulness of a sentinel lymph node biopsy is still not clear (109). In fact, SCC does not invade deeper tissues as quickly as cutaneous malignant melanoma. The reason consists in absence of lymphatic drainage in superficial dermis and epidermis. Therefore, SCC is less likely to spread via lymphatics. There are still no guidelines about how to approach regional nodal disease in patients with SCC. Moreover, available directions are based on studies concerning head and neck mucosal SCC (110). Patients affected by metastases from SCC spread to lymph nodes should be treated surgically, as well as patients with melanoma or Merkel cell carcinoma. When surgery is not indicated, e.g., for patient-related factors, a nonsurgical approach by a multidisciplinary group should be evaluated.

\section{Radiotherapy}

Radiotherapy (RT) may be applied in an adjuvant setting, after surgical resection, in patients with high-risk features. A host factors as immunosuppression is considered by the American Joint Committee of Cancer (AJCC) as a risk for having a poorer outcome when diagnosed with NMSC. Obviously, the presence of other risk factors such as location, particularly ears and lips, poor differentiation and perineural invasion (PNI) can worsen outcomes. American Society for Radiation Oncology (ASTRO) guidelines recommends postoperative radiotherapy (PORT) in the setting of chronic immunosuppression (111).

Bimodality therapy (surgery and PORT) is used in the context of immune suppression, especially with head and neck cutaneous SCC. As a matter of fact, it frequently presents a lower outcome than immunocompetent patients, with a significantly lower progression-free survival at 2 years $(p=0.002)(112)$. When necessary, adjuvant RT should not be delayed. It is demonstrated that exceeding a time of 6 weeks after the excision may worsen the prognosis (113). Irradiation volume must consider cancer location and risk factors, such as PNI, lymphatic and vascular invasion, to decide whether to include the first lymph node. The results of phase III TROG 05.01 trial (114) suggest no benefit in overall survival, disease free survival and locoregional relapse with the addition of weekly carboplatin to RT as adjuvant therapy.

$\mathrm{RT}$ is recommended as the only treatment modality in patients with NMSCs who cannot benefit from surgical resection. In fact, NMSCs can obtain an optimal local control because they are radio responsive carcinomas. Marconi et al. (115), using definitive RT, demonstrated that BCC had a 5- and 10year local control of $96 \%$ and $94 \%$, while for SCC 5- and 10-year control were $92 \%$ and $87 \%$, respectively. It is important to keep in mind that in case of underlying genetic syndromes RT is discouraged because of higher radio-sensitivity in patients affected by Li-Fraumeni or Gorlin syndrome, ataxia telangiectasia. Furthermore, connective tissue disorders represent a contraindication to treatment whenever not under control (111).

\section{Cryotherapy}

Cryotherapy represents a therapeutic option for BCC, although tissue destruction is not perfectly targeted. It is based on two consecutive 30 -second freeze-thaw cycles and is particularly effective on facial lesions, with a $95 \%$ cure rate (116).

\section{Electrodesiccation and Curettage}

Generally, these therapeutic options are considered only when assessing low-risk lesions. These techniques have a worse cosmetic yield than surgical excision, often ending in a round, hypopigmented and possibly hypertrophic scar (89). National Comprehensive cancer Network (NCCN) guidelines reported that curettage and electrodessication may be considered for small and low-risk primary SCC (117).

\section{Chemotherapy}

Systemic chemotherapy has a meaningful role in the management of local advanced and/or metastatic NMSC. Aggressive management with polychemotherapy should be considered for difficult to treat cases. Usually, monochemotherapy should be considered as a first-line treatment (50). Metastatic SCCs are notably difficult to treat, representing a challenge for clinicians. Platinum based chemotherapeutic 
agents, such as cisplatin or carboplatin, can be considered for local advanced and metastatic SCCs not amenable for surgical excision or radiotherapy. Other chemotherapeutic drugs, such as cyclophosphamide, bleomycin, doxorubicin, methotrexate and 5-FU, may also be used alone or in combination (118). However, guidelines for the use of classic chemotherapy in NMSC are based on low-level evidence, as the trials had several limitations, such as lack of randomization and heterogeneous patient populations. Recently, it has been highlighted that patients with stage I and II lip SCC can be successfully treated with monotherapy via superficial temporal artery administration of bleomycin, in order to obtain a cure in $70.8 \%$ of patients (119). Currently, chemotherapy is recommended in NCCN guidelines in a combination with radiotherapy, especially in localized, highrisk SCCs for patients who cannot undergo surgery (117). Before the advent of molecular target therapies, metastatic BCC had been treated with various conventional chemotherapeutic agents. However, metastatic BCC is rare, and the available literature about the effectiveness of these treatments is mostly episodic. In a short review collecting twelve elsewhere published cases treated with platinum, five showed complete response and four showed partial response (120).

\section{Immunotherapy and Target Therapy of NMSCs: New Promising Neoadjuvant Therapy}

Given actual evidence, targeted therapy and immunotherapy represent the frontiers in neoadjuvant therapy of NMSCs, being much more selective than traditional chemotherapy. Emerging clinical data (see Table 2) show that immunotherapy, particularly checkpoint inhibition, is a useful therapy option for advanced cSCC, while targeted therapy with sonic hedgehog pathway inhibitors results an effective treatment option for locally advanced or multiple BCC (121). The role of immune system has been linked to the occurrence of NMSCs by epidemiologic evidence that led to several studies about the immunology of NMSCs (122). These studies demonstrated the elevated number of neoantigens expressed by NMSCs' cells that could represent the right target for a successful immune therapy. These kinds of observations have led to ongoing clinical trials based on novel immunotherapies of NMSCs as a neoadjuvant approach (123). By definition, a neoadjuvant approach aims to reduce the size of the tumor, before the subsequent potentially curative techniques. Immunotherapy acts by inhibiting immune checkpoints, eventually improving the activity of the immune system against the tumoral cells and reducing regulatory $\mathrm{T}$ cell-mediated immunosuppression. Unfortunately, these new treatment options appear quite expensive; moreover, immunotherapy can cause important and irreversible adverse effects (121). A thorough knowledge of SCC carcinogenesis is needed to develop new treatment approaches. The main immune checkpoints include CTLA-4, PD-1 and PD-L1, while sonic hedgehog pathway inhibitors include Vismodegib and Sonidegib, that we briefly describe above.

\section{Anti-Programmed Cell Death Receptor-1 Immune Checkpoint Inhibitor Cemiplimab}

It is indicated for advanced or metastatic SCC in patients who are not amenable for surgery or radiotherapy. The phase I/II study (EMPOWER-CSCC-1) of patients with locally advanced or metastatic SCC has been the first trial that led to drug approval, producing a response rate of $47 \%$ in a cohort of 59 patients (124). Recently, this study led to the U.S. Food and Drug Administration approval of cemiplimab for locally advanced or metastatic SCC on September 28, 2018. The phase II clinical study of Cemiplimab in patients with advanced cutaneous SCC is ongoing and it is currently recruiting participants. (NCT02760498).

Another study (NCT03969004) is currently recruiting participants to study cemiplimab use in the adjuvant setting after surgery and radiation in patients with high risk of recurrence. Numerous ongoing clinical trials are studying the use of cemiplimab in patients with advanced BCC with a progression of disease while on Hedgehog pathway inhibitor therapy (125). Between them, the study (NCT03132636) is

TABLE 2 | Immune Checkpoint inhibitors.

\begin{tabular}{|c|c|c|}
\hline Stage of disease & scc & BCC \\
\hline I & Nivolumab \pm Ipilimumab(II) & N/A \\
\hline$\|$ & $\begin{array}{l}\text { Nivolumab } \pm \text { Ipilimumab (II) } \\
\text { Cemiplimab (II) }\end{array}$ & $\mathrm{N} / \mathrm{A}$ \\
\hline III & $\begin{array}{l}\text { Nivolumab } \pm \text { Ipilimumab (II) } \\
\text { Cemiplimab (II) }\end{array}$ & $\mathrm{N} / \mathrm{A}$ \\
\hline IVA & $\begin{array}{l}\text { Nivolumab } \pm \text { Ipilimumab (II) } \\
\text { Avelumab (II) } \\
\text { Cemiplimab (II) } \\
\text { Pembrolizumab (II) }\end{array}$ & Nivolumab \pm Ipilimumab (II) \\
\hline IVB & $\begin{array}{l}\text { Nivolumab (II) } \\
\text { Avelumab (II) } \\
\text { Cemiplimab (II) } \\
\text { Pembrolizumab (II) }\end{array}$ & Nivolumab \pm Ipilimumab (II) \\
\hline
\end{tabular}

Immune Checkpoint inhibitors currently under investigation for the treatment of squamous cell carcinoma and basal cell carcinoma. Between brackets the phase of the study. SCC, squamous cell carcinoma; BCC, basal cell carcinoma; N/A, not applicable. Data extracted from https://clinicaltrials.gov/. 
active, not recruiting. Another ongoing clinical trial is studying CTLA-4/PD-1 combinations, such as ipilimumab/nivolumab for treatment of advanced BCC. This study (NCT03521830) is currently recruiting participants with locally advanced or metastatic BCC.

\section{Pembrolizumab}

There are currently ongoing studies that are investigating the treatment of recurrent or metastatic cSCC (126). Between them, (NCT02964559) is an active study, not recruiting participants. It is also being evaluated in advanced SCC (NCT03284424), an active study, not recruiting for treatment of recurrent or metastatic cSCC.

\section{Nivolumab}

It is also being evaluated in advanced SCC: (NCT04204837) is an active study, not recruiting.

\section{Anti-Programmed Cell Death Ligand-1 Avelumab}

Several ongoing studies for advanced SCC are investigating avelumab with or without cetuximab (121). The study (NCT03944941) is currently open to enrollment. Another study, (NCT03737721) is currently recruiting participants with unresectable SCC treated with avelumab and radical radiotherapy. This study is called UNSCARRed study.

\section{Atezolizumab}

The study (NCT03108131) studies how cobimetinib/ atezolizumab association works in treating participants with rare tumors that have spread to other places in the body (advanced) or that does not respond to treatment (refractory). This study is currently recruiting participants. Cobimetinib may block some of the enzymes involved in cell growth. So that, immunotherapy with monoclonal antibodies, such as atezolizumab, could interfere with the capability of tumor cells to grow and spread.

\section{Cosibelimab}

Cosibelimab is a fully human monoclonal antibody of IgG1 subtype that directly blocks its interactions with the Programmed Death-1 (PD-1) and B7.1 receptors (121). The study (NCT03212404), based on cosibelimab/atezolizumab association, is currently recruiting participants. The aim of this study is to assess the safety, tolerability and efficacy of CK-301 when administered intravenously as a single agent to subjects with recurrent or metastatic cancers.

\section{Anti-Cytotoxic T-Lymphocyte-Associated Protein 4 Immune Checkpoint Inhibition Ipilimumab}

Emerging data showing ipilimumab use in SCC are limited to case reports. A patient with metastatic cSCC had a durable remission of both malignancies. Concerning BCC, there is an ongoing study regarding locally-advanced unresectable or metastatic BCC which investigates ipilimumab in association with nivolumab in one of the arms (NCT03521830) (127). This study is currently open to enrollment.

\section{Hedgehog Pathway Inhibitors: Vismodegib and Sonidegib}

Genetic and molecular studies have highlighted genetic mutations in the hedgehog signaling pathway characterize almost all BCCs. These alterations result in excessive activation leading to uncontrolled proliferation of basal cells. In addition, they determine loss of function of patched homologue 1 (PTCH1). PTCH1 blocks the signaling activity of smoothened homologue (SMO), a seven-transmembrane protein.

Vismodegib and sonidegib are two anti-tumor drugs targeting the $\mathrm{HH}$ pathway, called hedgehog pathway inhibitors (HPIs). Currently, there are no recommendations about when to prefer one molecule rather than the other. Moreover, these molecules have similar efficacy and tolerability, although they differ under a pharmacokinetic aspect (128). As a matter of fact, both are metabolized through cytochrome P450. Vismodegib is prevalently metabolized by $\mathrm{CYP} 2 \mathrm{C}$, while sonidegib passes through CY3A4. Therefore, CYP3A4 inhibitors increases the blood concentration of sonidegib. Among them, ritonavir e saquinavir, two antiretroviral drugs. Whenever it is not possible to avoid the simultaneous use of sonidegib and strong inhibitors of CYP3A4, a dose reduction to sonidegib $200 \mathrm{mg}$ every second day is recommended (129). Muscle spasms, alopecia, dysgeusia and weight loss are the most frequent side effects described in the literature. Of interest, many cases of SCC have been observed in patients treated with vismodegib for BCC therapy or single agent (BRAF) inhibitors, such as vemurafenib, for melanoma therapy (130).

All the current conventional treatments and ongoing trials are summarized in Table 3. Further studies are required to better understand the correct management of the drug, alternative dosing regimens and differences with the other HPIs.

\section{Target Therapy in PLWH}

Immunotherapy has paved new paths for treatment of HIVrelated cancers and, thanks to monoclonal antibodies and immunomodulatory drugs, have shown to be effective in HIVrelated cancers. In particular, the effectiveness of checkpoint inhibitors targeting the PD-1/PD-L1 pathway in the treatment of many malignancies in PLWH it has been suggested by recent data, hopefully stronger evidence on this matter will follow with the inclusion of PLWH in immune-oncology studies. Recently, ASCO and the Food and Drug Association (FDA) have provided guidance to include PLWH in clinical trials on neoplastic diseases.

A recent FDA-approved sonic hedgehog ( $\mathrm{SHH}$ ) signaling pathway inhibitor, Vismodegib, can be used to treat locally advanced, metastatic and recurrent BCCs that are inoperable and cannot be treated with radiotherapy, showing promising results (131). Although this molecule seems to be a safe option for those patients that cannot undergo surgery for advanced and metastatic BCC, in high-risk patients the optimal treatment protocol is unknown. The safety of Vismodegib in PLWH and its interactions with cART are not well known. Recently, Scalvenzi et al. have described a case-report of a HIV positive patient with an inoperable ulcerative BCC of the ear. 
TABLE 3 | Conventional and New promising neoadjuvant therapies.

CONVENTIONAL THERAPY

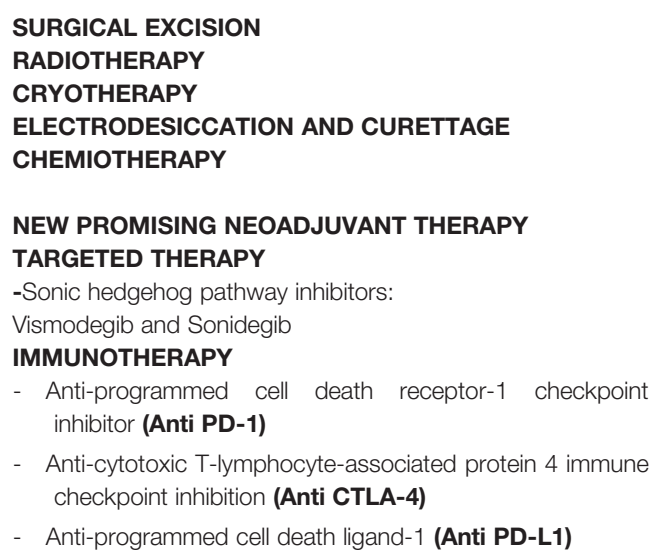

Conventional and New promising neoadjuvant therapies. SCC, squamous cell carcinoma; CSCC, cutaneous squamous cell carcinoma; BCC, basal cell carcinoma.

After a specialistic evaluation also of the immune status (high CD4 $\mathrm{T}$ cell count) the patient started oral Vismodegib $150 \mathrm{mg}$ daily. In about 6 months of therapy the patient obtained a complete resolution, after which Vismodegib was discontinued. The article reports good tolerance and no interactions between Vismodegib and the previous cART (132). Reports on SHH inhibitors in immunocompromised patients witch locally advanced or metastasizing BCC are rare (133). Effectual use of Vismodegib and the lack of drug to drug interaction with cART (tenofovir/emtricitabine/rilpivirine) has been described in a single case (132). Recently, Hoffmann V. et al. have described a successful case of treatment with Sonidegib in a patient on cART. However, it's mandatory to evaluate the risk of interactions between cART and antiblastic chemotherapy, target therapy and immunotherapy (134). In fact, it is true that the new antiretroviral drugs (135) are less toxic but they still have longterm side effects that need to be careful evaluated (136).

\section{CONCLUSIONS AND FUTURE PERSPECTIVES}

PLWH have an elevated propensity to develop cancers compared to the general population. It has been clearly shown that in this population immunosuppression and concomitant infection with oncogenic viruses play an important role. NMSCs are the most frequent cause of cutaneous malignancy in PLWH, and they represent a new oncologic challenge due increasing age of HIVinfected patients. In this paper, we tried to review the incidence of NMSCs among PLWH, any different clinical presentations of squamous cell and basal cell carcinoma between PLWH and HIV negative persons and any differences in efficacy and safety of treatments and response to immunomodulators (see Table 4). According to several authors ratios of BCC and SCC are similar between PLWH and HIV negative persons (4:1) (140), with BCC essentially more frequent than SCC. PLWH with NMSCs tend to be younger, to have a higher risk of local recurrence and to have an overall poorer outcome. The main risk factors for NMSCs are similar to HIV negative individuals. Superficial BCC is the most frequent variant and is more often found on the trunk and in multiple lesions. SCC tends to be more aggressive in HIV infected people and it presents at significantly younger age, with higher risk of local recurrence and metastasis (141). The treatment of SCC in people with HIV should be at least aggressive as the treatment in HIV seronegative individuals. There is no strong evidence of how the depth of the immune compromission (CD4 counts) directly influence the risk of NMSCs, and this evidence supports mainly the risk of SCC rather than BCC. It is mandatory to suggest to PLWH a proper screening of all precancerous lesions besides a careful prevention with sun avoidance and use of sunscreen. Notably, there is a lack of official recommendation and guidelines on these subjects. Recently, Vismodegib and Sonidegib, two hedgehog signaling pathway inhibitors, have been approved to treat unresectable BCCs that are not amenable for surgery and radiotherapy. It is difficult to compare the efficacy of Sonidegib and Vismodegib due to the absence of trials designed to prove it and also because the first is only approved for locally advanced BCC while the last is also used for metastasizing BCC (128). It is time to answer to this lack of knowledge with appropriate trials that study the role of targeted therapy for BCC, in PLWH that result to be inoperable. The effectiveness of checkpoint inhibitors targeting the PD-1/PD-L1 pathway in the treatment of many malignancies in PLWH it has been suggested by recent data, hopefully stronger evidence on this matter will follow. In order to improve knowledge, PLWH must be included in immuneoncology studies. In conclusion, the treatment of advanced NMSC represents still an important challenge for clinician, mainly because of the lack of high-quality evidence and randomized trials. Further studies are required to focus on the best therapeutic approaches to NMSCs and mostly on the impact of cancer screening interventions among HIV-infected patients, in order to improve cancer diagnosis at an earlier stage. Further 
TABLE 4 | Synoptic picture with differences between PLWH and immunocompetent.

\begin{tabular}{|c|c|c|}
\hline & GENERAL POPULATION & HIV POSITIVE PATIENTS \\
\hline RATIOS BCC/SCC & $4: 1(30)$ & $4: 1(33)$ \\
\hline MORE FREQUENT & Nodular (75) & Superficial (137) \\
\hline \multicolumn{3}{|l|}{ SUBTYPE OF BCC } \\
\hline PREVALENCE M/W & $\begin{array}{l}\text { Slight male predilection } \\
\text { (after age of } 45 \text { years) (138) }\end{array}$ & Increased risk of NMSC in both male and female patients (139) \\
\hline AGE AT DIAGNOSIS & $60-70$ years & Tendency to earlier age ( 45 years) (83) \\
\hline $\begin{array}{l}\text { RISK FACTORS } \\
\text { FOR }\end{array}$ & $\begin{array}{l}\text { Chronic sun-exposure, fair phenotypic features, family } \\
\text { history, older age, genetic mutations }\end{array}$ & $\begin{array}{l}\text { The same as for general population plus immunodeficiency and coinfection with } \\
\text { oncogenic viruses (83) }\end{array}$ \\
\hline \multicolumn{3}{|l|}{ DEVELOPMENT OF } \\
\hline \multicolumn{3}{|l|}{ NMSCs } \\
\hline $\begin{array}{l}\text { ANATOMIC } \\
\text { DISTRIBUTION }\end{array}$ & $\begin{array}{l}\text { Sun-exposed areas (more frequent on head and neck } \\
\text { regions) }\end{array}$ & Trunk and extremities (generally lesions are multiple) (83) \\
\hline CLINICAL COURSE & $\begin{array}{l}\text { Usually indolent; nevertheless, metastatic forms lead to poor } \\
\text { patient outcome }\end{array}$ & Generally more aggressive compared to the general population (83) \\
\hline $\begin{array}{l}\text { RISK METASTATIC } \\
\text { DISEASE }\end{array}$ & $\begin{array}{l}\text { Generally BCC shows minimal metastatic potential (88); SCC } \\
\text { has a } 4 \% \text { annual incidence of metastatic disease (90) }\end{array}$ & Higher compared to the general population (83) \\
\hline TREATMENT & $\begin{array}{l}\text { Full thickness Treatment }(93) \\
\text { Surgical excision } \\
\text { Mohs micro-graphic surgery } \\
\text { Radiotherapy } \\
\text { Superficial ablative techniques } \\
\text { Targeted Therapy }\end{array}$ & $\begin{array}{l}\text { The same as standard of care for general population. However, it's mandatory to } \\
\text { evaluate the risk of drug interactions (between cART and other treatments) (134) }\end{array}$ \\
\hline
\end{tabular}

studies are needed to learn and apply pathogenetic insights to obtain new therapeutic options and correlate the degree of HIVrelated immunodeficiency with disease outcome.

\section{AUTHOR CONTRIBUTIONS}

$\mathrm{ER}, \mathrm{MB}$, and GN designed the study. ER, MM, MB, and MC performed the screening of articles following the inclusion criteria. ER, MM, and FF wrote the article. CG, MB, and GN

\section{REFERENCES}

1. Venanzi Rullo E, Cannon L, Pinzone MR, Ceccarelli M, Nunnari G, O'Doherty U. Genetic Evidence That Naive T Cells Can Contribute Significantly to the Human Immunodeficiency Virus Intact Reservoir: Time to Re-Evaluate Their Role. Clin Infect Dis (2019) 69:2236-7. doi: $10.1093 / \mathrm{cid} / \mathrm{ciz} 378$

2. Venanzi Rullo E, Pinzone MR, Cannon L, Weissman S, Ceccarelli M, Zurakowski R, et al. Persistence of an Intact HIV Reservoir in Phenotypically Naive T Cells. JCI Insight (2020) 5:105. doi: 10.1172/jci.insight.133157

3. Atteritano M, Mirarchi L, Venanzi Rullo E, Santoro D, Iaria C, Catalano A, et al. Vitamin D Status and the Relationship With Bone Fragility Fractures in HIV-Infected Patients: A Case Control Study. Int J Mol Sci (2018) 19 (1):119. doi: 10.3390/ijms19010119

4. Facciolà $\mathrm{A}$, Venanzi Rullo E, Ceccarelli M, D’Andrea F, Coco M, Micali C, et al. Malignant Melanoma in HIV: Epidemiology, Pathogenesis, and Management. Dermatol Ther (2019) 33(1):e13180. doi: 10.1111/dth.13180

5. Facciolà A, Venanzi Rullo E, Ceccarelli M, D’Aleo F, Visalli G, Pinzone MR, et al. Hodgkin's Lymphoma in People Living With HIV: Epidemiology and Clinical Management. World Cancer Res J (2019) 6:e1295. doi: 10.32113/ wcri_20195_1295

6. D’Andrea F, Pellicanò GF, Venanzi Rullo E, Nunnari G, Ceccarelli M. Cervical Cancer in Women Living With HIV: A Review of the Literature. World Cancer Res J (2019) 6:1-6. doi: 10.32113/wcrj_20193_1224 supervised the part of diagnosis and treatment. All authors contributed to the article and approved the submitted version.

\section{SUPPLEMENTARY MATERIAL}

The Supplementary Material for this article can be found online at: https://www.frontiersin.org/articles/10.3389/fonc.2021.689789/ full\#supplementary-material

7. D’Andrea F, Ceccarelli M, Facciolà A, Nunnari G, Pellicanò GF. Breast Cancer in Women Living With HIV. Eur Rev Med Pharmacol Sci (2019) 23:1158-64. doi: 10.26355/eurrev_201902_17007

8. Facciolà A, Ceccarelli M, Venanzi Rullo E, D'Aleo F, Condorelli F, Visalli G, et al. Prostate Cancer in HIV-Positive Patients- a Review of the Literature. World Cancer Res J (2018) 5:e1136. doi: 10.32113/wcrj_20189_1136

9. Visalli G, Facciolà A, D'Aleo F, Pinzone MR, Condorelli F, Picerno I, et al. HPV and Urinary Bladder Carcinoma: A Review of the Literature. World Cancer Res J (2018) 5:e1038. doi: 10.32113/wcrj_20183_1038

10. D’Aleo F, Cama BAV, Paolucci IA, Venanzi Rullo E, Condorelli F, Facciolà A, et al. New and Old Assumptions on Lung Cancer in People Living With HIV. World Cancer Res J (2018) 5:e1036. doi: 10.32113/wcrj_20183_1036

11. Ceccarelli M, Venanzi Rullo E, Facciolà A, Madeddu G, Cacopardo B, Taibi R, et al. Head and Neck Squamous Cell Carcinoma and Its Correlation With Human Papillomavirus in People Living With HIV: A Systematic Review. Oncotarget (2018) 9:17171-80. doi: 10.18632/oncotarget.24660

12. Ceccarelli M, Condorelli F, Venanzi Rullo E, Pellicanò GF. Improving Access and Adherence to Screening Tests for Cancers: A New, Though Old, Challenge in the HIV Epidemics. World Cancer Res J (2018) 5:e1030. doi: $10.1093 /$ cid/ciu773

13. D’Andrea F, Ceccarelli M, Venanzi Rullo E, Facciolà A, D'Aleo F, Cacopardo B, et al. Cancer Screening in Hiv-Infected Patients: Early Diagnosis in a High-Risk Population. World Cancer Res J (2018) 5:e1130. doi: 10.32113/ wcrj_20189_1130 
14. D'Aleo F, Ceccarelli M, Facciolà A, Condorelli F, Pinzone MR, Cacopardo B, et al. HIV and Colorectal Cancer. New Insights and Review of the Literature. World Cancer Res J (2018) 5:e1122. doi: 10.32113/wcrj_20189_1122

15. Khazaei Z, Ghorat F, Jarrahi AM, Adineh A, Sohrabivafa M, Goodarzi E. Global Incidence and Mortality of Skin Cancer by Histological Subtype and Its Relationship With the Human Development Index (HDI) - An Ecology Study in 2018. World Cancer Res J (2019) 6:1-14. doi: 10.4103/AIHB. AIHB_2_19

16. Ceccarelli M, Venanzi Rullo E, Vaccaro M, Facciolà A, D’Aleo F, Paolucci IA, et al. HIV-Associated Psoriasis: Epidemiology, Pathogenesis, and Management. Dermatol Ther (2018) 32(2):e12806. doi: 10.1111/dth.12806

17. Berretta M, Martellotta F, Di Francia R, Spina M, Vaccher E, Balestreri L, et al. Clinical Presentation and Outcome of Non-AIDS Defining Cancers, in HIV-Infected Patients in the ART-Era: The Italian Cooperative Group on AIDS and Tumors Activity. Eur Rev Med Pharmacol Sci (2015) 19:3619-34.

18. La Ferla L, Pinzone MR, Nunnari G, Martellotta F, Lleshi A, Tirelli U, et al. Kaposi's Sarcoma in HIV-Positive Patients: The State of Art in the HAARTEra. Eur Rev Med Pharmacol Sci (2013) 17:2354-65.

19. Martellotta F, Berretta M, Cacopardo B, Fisichella R, Schioppa O, Zanghì A, et al. Clinical Presentation and Outcome of Squamous Cell Carcinoma of the Anus in HIV-Infected Patients in the HAART-Era: A GICAT Experience. Eur Rev Med Pharmacol Sci (2012) 16:1283-91.

20. Berretta M, Garlassi E, Cacopardo B, Cappellani A, Guaraldi G, Cocchi S, et al. Hepatocellular Carcinoma in HIV-Infected Patients: Check Early, Treat Hard. Oncologist (2011) 16:1258-69. doi: 10.1634/theoncologist.2010-0400

21. Simonelli C, Tedeschi R, Gloghini A, Talamini R, Bortolin MT, Berretta M, et al. Plasma HHV-8 Viral Load in HHV-8-Related Lymphoproliferative Disorders Associated With HIV Infection. J Med Virol (2009) 81:888-96. doi: $10.1002 /$ jmv. 21349

22. Zanet E, Berretta M, Benedetto FD, Talamini R, Ballarin R, Nunnari G, et al. Pancreatic Cancer in HIV-Positive Patients. Pancreas (2012) 41:1331-5. doi: 10.1097/MPA.0b013e31824a0e40

23. Ceccarelli M, Venanzi Rullo E, Marino MA, D’Aleo F, Pellicanò GF, D’Andrea F, et al. Non-AIDS Defining Cancers: A Comprehensive Update on Diagnosis and Management. Eur Rev Med Pharmacol Sci (2020) 24:384975. doi: 10.26355/eurrev_202004_20852

24. Ceccarelli M, Facciolà A, Taibi R, Pellicanò GF, Nunnari G, Venanzi Rullo E. The Treatment of Kaposi's Sarcoma: Present and Future Options, A Review of the Literature. Eur Rev Med Pharmacol Sci (2019) 23:7488-97. doi: 10.26355/eurrev_201909_18860

25. Guarneri C, Tchernev G, Bevelacqua V, Lotti T, Nunnari G. The Unwelcome Trio: HIV Plus Cutaneous and Visceral Leishmaniasis. Dermatol Ther (2016) 29:88-91. doi: 10.1111/dth.12303

26. D’Aleo F, Ceccarelli M, Venanzi Rullo E, Pellicanò GF, Nunnari G. Anal Cancer in People Living With HIV: The Importance of the Screening and of Early Diagnosis. World Cancer Res J (2019) 6:1-9. doi: 10.32113/wcrj_ 20196_1319

27. Leiter U, Eigentler T, Garbe C. Epidemiology of Skin Cancer. In: Advances in Experimental Medicine and Biology. New York, NY: Springer (2014). p. 12040. doi: 10.1007/978-1-4939-0437-2_7

28. Eide MJ, Krajenta R, Johnson D, Long JJ, Jacobsen G, Asgari MM, et al. Identification of Patients With Nonmelanoma Skin Cancer Using Health Maintenance Organization Claims Data. Am J Epidemiol (2010) 171:123-8. doi: 10.1093/aje/kwp352

29. Bray F, Ferlay J, Soerjomataram I, Siegel RL, Torre LA, Jemal A. Global Cancer Statistics 2018: GLOBOCAN Estimates of Incidence and Mortality Worldwide for 36 Cancers in 185 Countries. CA Cancer J Clin (2018) 68:394-424. doi: 10.3322/caac.21492

30. Kaira PS, Han J, Schmults CD. Cutaneous Squamous Cell Carcinoma: Estimated Incidence of Disease, Nodal Metastasis, and Deaths From Disease in the United States. J Am Acad Dermatol (2012) 2013) 68:95766. doi: 10.1016/j.jaad.2012.11.037

31. Engels EA, Pfeiffer RM, Goedert JJ, Virgo P, McNeel TS, Scoppa SM, et al. Trends in Cancer Risk Among People With AIDS in the United States 19802002. AIDS (2006) 20:1645-54. doi: 10.1097/01.aids.0000238411.75324.59

32. Palella FJ, Delaney KM, Moorman AC, Loveless MO, Fuhrer J, Satten GA, et al. Declining Morbidity and Mortality Among Patients With Advanced
Human Immunodeficiency Virus Infection. N Engl J Med (1998) 338:85360. doi: 10.1056/NEJM199803263381301

33. Chang AY, Doiron P, Maurer T. Cutaneous Malignancies in HIV. Curr Opin HIV AIDS (2017) 12:57-62. doi: 10.1097/COH.0000000000000338

34. Nunnari G, Berretta M, Pinzone MR, Di Rosa M, Berretta S, Cunsolo G, et al. Hepatocellular Carcinoma in HIV Positive Patients. Eur Rev Med Pharmacol Sci (2012) 16:1257-70.

35. Omland SH, Ahlström MG, Gerstoft J, Pedersen G, Mohey R, Pedersen C, et al. Risk of Skin Cancer in Patients With HIV: a Danish Nationwide Cohort Study. J Am Acad Dermatol (2018) 79:689-95. doi: 10.1016/j.jaad.2018. 03.024

36. Clifford GM, Polesel J, Rickenbach Mon behalf of the Swiss HIV Cohort Study, , Dal Maso L, Keiser O, et al. Cancer Risk in the Swiss HIV Cohort Study: Associations With Immunodeficiency, Smoking, and Highly Active Antiretroviral Therapy. JNCI J Natl Cancer Inst (2005) 97:425-32. doi: $10.1093 /$ jnci/dji072

37. Silverberg MJ, Leyden W, Warton EM, Quesenberry CP, Engels EA, Asgari MM. HIV Infection Status, Immunodeficiency, and the Incidence of NonMelanoma Skin Cancer. J Natl Cancer Inst (2013) 105:350-60. doi: 10.1093/ jnci/djs529

38. Chiu CS, Lin CY, Kuo TT, Kuan YZ, Chen MJ, Ho HC, et al. Malignant Cutaneous Tumors of the Scalp: A Study of Demographic Characteristics and Histologic Distributions of 398 Taiwanese Patients. J Am Acad Dermatol (2007) 56:448-52. doi: 10.1016/j.jaad.2006.08.060

39. Fahradyan A, Howell AC, Wolfswinkel EM, Tsuha M, Sheth P, Wong AK. Updates on the Management of Non-Melanoma Skin Cancer (NMSC). Healthcare (Basel) (2017) 5:82. doi: 10.3390/healthcare5040082

40. Harwood CA, Toland AE, Proby CM, Euvrard S, Hofbauer GFL, Tommasino M, et al. The Pathogenesis of Cutaneous Squamous Cell Carcinoma in Organ Transplant Recipients. Br J Dermatol (2017) 177:1217-24. doi: 10.1111/bjd.15956

41. Jambusaria-Pahlajani A, Kanetsky PA, Karia PS, Hwang W-T, Gelfand JM, Whalen FM, et al. Evaluation of AJCC Tumor Staging for Cutaneous Squamous Cell Carcinoma and a Proposed Alternative Tumor Staging System. JAMA Dermatol (2013) 149:402-10. doi: 10.1001/jamadermatol. 2013.2456

42. Lang PG, Braun MA, Kwatra R. Aggressive Squamous Carcinomas of the Scalp. Dermatol Surg (2006) 32:1163-70. doi: 10.1111/j.1524-4725.2006. 32258.x

43. Gupta SK, Sandhir RK, Jaiswal AK, Kumar S. Marjolin's Ulcer of the Scalp Invading Calvarial Bone, Dura and Brain. J Clin Neurosci (2005) 12:693-5. doi: 10.1016/j.jocn.2004.08.030

44. Zanetti R, Rosso S, Martinez C, Navarro C, Schraub S, SanchoGarnier H, et al. The Multicentre South European Study "Helios".1. Skin Characteristics and Sunburns in Basal Cell and Squamous Cell Carcinomas of the Skin. Br J Cancer (1996) 73:1440-6. doi: 10.1038/bjc.1996.274

45. Saladi RN, Persaud AN. The Causes of Skin Cancer: a Comprehensive Review. Drugs Today (Barc) (2005) 41:37-53. doi: 10.1358/dot.2005.41.1. 875777

46. Karagas MR, Nelson HH, Zens MS, Linet M, Stukel TA, Spencer S, et al. Squamous Cell and Basal Cell Carcinoma of the Skin in Relation to Radiation Therapy and Potential Modification of Risk by Sun Exposure. Epidemiology (2007) 18:776-84. doi: 10.1097/EDE.0b013e3181567ebe

47. Kaae J, Boyd HA, Hansen AV, Wulf HC, Wohlfahrt J, Melbye M. Photosensitizing Medication Use and Risk of Skin Cancer. Cancer Epidemiol Biomarkers Prev (2010) 19:2942-9. doi: 10.1158/1055-9965.EPI10-0652

48. Pellegrini C, Maturo MG, Di Nardo L, Ciciarelli V, Gutiérrez GarcíaRodrigo C, Fargnoli MC. Understanding the Molecular Genetics of Basal Cell Carcinoma. Int J Mol Sci (2017) 18(11):2485. doi: 10.3390/ijms18112485

49. Bresler SC, Padwa BL, Granter SR. Nevoid Basal Cell Carcinoma Syndrome (Gorlin Syndrome). Head Neck Pathol (2016) 10:119-24. doi: 10.1007/ s12105-016-0706-9

50. Stratigos A, Garbe C, Lebbe C, Malvehy J, del Marmol V, Pehamberger H, et al. Diagnosis and Treatment of Invasive Squamous Cell Carcinoma of the Skin: European Consensus-Based Interdisciplinary Guideline. Eur J Cancer (2015) 51:1989-2007. doi: 10.1016/j.ejca.2015.06.110 
51. Ventura A, Pellegrini C, Cardelli L, Rocco T, Ciciarelli V, Peris K, et al. Telomeres and Telomerase in Cutaneous Squamous Cell Carcinoma. Int J Mol Sci (2019) 20(6):1333. doi: 10.3390/ijms20061333

52. Martincorena I, Roshan A, Gerstung M, Ellis P, Van Loo P, McLaren S, et al. High Burden and Pervasive Positive Selection of Somatic Mutations in Normal Human Skin. Science (2015) 348:880-6. doi: 10.1126/science.aaa6806

53. Muehleisen B, Jiang SB, Gladsjo JA, Gerber M, Hata T, Gallo RL. Distinct Innate Immune Gene Expression Profiles in Non-Melanoma Skin Cancer of Immunocompetent and Immunosuppressed Patients. PloS One (2012) 7: e40754. doi: 10.1371/journal.pone.0040754

54. Akira S, Hemmi H. Recognition of Pathogen-Associated Molecular Patterns by TLR Family. Immunol Lett (2003) 85:85-95. doi: 10.1016/s0165-2478(02) 00228-6

55. Eiró N, Ovies C, Fernandez-Garcia B, Álvarez-Cuesta CC, González L, González LO, et al. Expression of TLR3, 4, 7 and 9 in Cutaneous Malignant Melanoma: Relationship With Clinicopathological Characteristics and Prognosis. Arch Dermatol Res (2013) 305:59-67. doi: 10.1007/s00403-012$1300-y$

56. Gupta AK, Cherman AM, Tyring SK. Viral and Nonviral Uses of Imiquimod: A Review. J Cutan Med Surg (2004) 8:338-52. doi: 10.1007/ s10227-005-0023-5

57. Kutikhin AG. Association of Polymorphisms in TLR Genes and in Genes of the Toll-Like Receptor Signaling Pathway With Cancer Risk. Hum Immunol (2011) 72:1095-116. doi: 10.1016/j.humimm.2011.07.307

58. Russo I, Cona C, Saponeri A, Bassetto F, Baldo V, Alaibac M. Association Between Toll-Like Receptor 7 Gln11leu Single-Nucleotide Polymorphism and Basal Cell Carcinoma. BioMed Rep (2016) 4:459-62. doi: 10.3892/ br.2016.597

59. Malaponte G, Hafsi S, Polesel J, Castellano G, Spessotto P, Guarneri C, et al. Tumor Microenvironment in Diffuse Large B-Cell Lymphoma: Matrixmetalloproteinases Activation Is Mediated by Osteopontin Overexpression. Biochim Biophys Acta (2016) 1863:483-9. doi: 10.1016/ j.bbamcr.2015.09.018

60. Dotto GP, Rustgi AK. Squamous Cell Cancers: A Unified Perspective on Biology and Genetics. Cancer Cell (2016) 29:622-37. doi: 10.1016/ j.ccell.2016.04.004

61. Euvrard S, Kanitakis J, Claudy A. Skin Cancers After Organ Transplantation. N Engl J Med (2003) 348:1681-91. doi: 10.1056/NEJMra022137

62. Vinay DS, Ryan EP, Pawelec G, Talib WH, Stagg J, Elkord E, et al. Immune Evasion in Cancer: Mechanistic Basis and Therapeutic Strategies. Semin Cancer Biol (2015) 35 Suppl:S185-98. doi: 10.1016/j.semcancer.2015.03.004

63. Lindström LS, Yip B, Lichtenstein P, Pawitan Y, Czene K. Etiology of Familial Aggregation in Melanoma and Squamous Cell Carcinoma of the Skin. Cancer Epidemiol Biomarkers Prev (2007) 16:1639-43. doi: 10.1158/ 1055-9965.EPI-07-0047

64. Al-Rohil RN, Tarasen AJ, Carlson JA, Wang K, Johnson A, Yelensky R, et al. Evaluation of 122 Advanced-Stage Cutaneous Squamous Cell Carcinomas by Comprehensive Genomic Profiling Opens the Door for New Routes to Targeted Therapies. Cancer (2016) 122:249-57. doi: 10.1002/cncr.29738

65. Hernandez-Ramirez RU, Shiels MS, Dubrow R, Engels EA. Cancer Risk in HIV-Infected People in the USA From 1996 to 2012: A Population-Based, Registry-Linkage Study. Lancet HIV (2017) 4:E495-504. doi: 10.1016/S23523018(17)30125-X

66. Pope M, Betjes M, Romani N, Hirmand H, Cameron P, Hoffman L, et al. Conjugates of Dendritic Cells and Memory T-Lymphocytes From Skin Facilitate Productive Infection With HIV-1. Cell (1994) 78:389-98. doi: 10.1016/0092-8674(94)90418-9

67. Gordin FM, Hartigan PM, Klimas NG, Zollapazner SB, Simberkoff MS, Hamilton JD. Delayed-Type Hypersensitivity Skin-Tests Are an Independent Predictor of Human-Immunodeficiency-Virus Disease Progression. J Infect Dis (1994) 169:893-7. doi: 10.1093/infdis/169.4.893

68. Guo H-G, Pati S, Sadowska M, Charurat M, Reitz M. Tumorigenesis by Human Herpesvirus 8 vGPCR Is Accelerated by Human Immunodeficiency Virus Type 1 Tat. J Virol (2004) 78:9336-42. doi: 10.1128/JVI.78.17.9336-9342.2004

69. Li CJ, Wang C, Friedman DJ, Pardee AB. Reciprocal Modulations Between P53 and Tat of Human Immunodeficiency Virus Type 1. Proc Natl Acad Sci (1995) 92:5461-4. doi: 10.1073/pnas.92.12.5461
70. Wistuba II, Behrens C, Milchgrub S, Virmani AK, Jagirdar J, Thomas B, et al. Comparison of Molecular Changes in Lung Cancers in HIV-Positive and HIV-Indeterminate Subjects. JAMA (1998) 279:1554-9. doi: 10.1001/ jama.279.19.1554

71. Corallini A, Campioni D, Rossi C, Albini A, Possati L, Rusnati M, et al. Promotion of Tumour Metastases and Induction of Angiogenesis by Native HIV-1 Tat Protein From BK Virus/Tat Transgenic Mice. AIDS (1996) 10:701-10. doi: 10.1097/00002030-199606001-00003

72. Burgi A, Brodine S, Wegner S, Milazzo M, Wallace MR, Spooner K, et al. Incidence and Risk Factors for the Occurrence of Non-AIDS-Defining Cancers Among Human Immunodeficiency Virus-Infected Individuals. Cancer (2005) 104:1505-11. doi: 10.1002/cncr.21334

73. Tedeschi R, Caggiari L, Silins I, Kallings I, Andersson-Ellstrom A, De Paoli P, et al. Seropositivity to Human Herpesvirus 8 in Relation to Sexual History and Risk of Sexually Transmitted Infections Among Women. Int J Cancer (2000) 87:232-5. doi: 10.1002/1097-0215(20000715)87:2<232::AIDIJC13>3.0.CO;2-T

74. Berretta M, Cinelli R, Martellotta F, Spina M, Vaccher E, Tirelli U. Therapeutic Approaches to AIDS-Related Malignancies. Oncogene (2003) 22:6646-59. doi: 10.1038/sj.onc.1206771

75. Di Stefani A, Chimenti S. Basal Cell Carcinoma: Clinical and Pathological Features. G Ital Dermatol Venereol (2015) 150:385-91.

76. Puoti M, Bruno R, Soriano V, Donato F, Gaeta GB, Quinzan GP, et al. Hepatocellular Carcinoma in HIV-Infected Patients: Epidemiological Features, Clinical Presentation and Outcome. AIDS (2004) 18:2285-93. doi: 10.1097/00002030-200411190-00009

77. D’Andrea F, Venanzi Rullo E, Marino A, Moscatt V, Celesia BM, Cacopardo B, et al. Hepatitis B Virus Infection and Hepatocellular Carcinoma in PLWH: Epidemiology, Pathogenesis and Treatment. World Cancer Res J (2020) 7:e1537. doi: 10.32113/wcrj_20203_1537

78. D'Aleo F, Ceccarelli M, Facciolà A, Di Rosa M, Pinzone MR, Condorelli F, et al. Hepatitis C-Related Hepatocellular Carcinoma: Diagnostic and Therapeutic Management in HIV-Patients. Eur Rev Med Pharmacol Sci (2017) 21:5859-67. doi: 10.26355/eurrev_201712_14035

79. D’Andrea F, Venanzi Rullo E, Facciolà A, Di Rosa M, Condorelli F, Marino A, et al. Epstein Barr Virus Related Cancer in People Living With HIV: A Review of the Literature. World Cancer Res J (2020) 7:e1512. doi: 10.32113/ wcrj_20203_1512

80. Arron ST, Ruby JG, Dybbro E, Ganem D, Derisi JL. Transcriptome Sequencing Demonstrates That Human Papillomavirus Is Not Active in Cutaneous Squamous Cell Carcinoma. J Invest Dermatol (2011) 131:174553. doi: 10.1038/jid.2011.91

81. Wang J, Aldabagh B, Yu J, Arron ST. Role of Human Papillomavirus in Cutaneous Squamous Cell Carcinoma: A Meta-Analysis. J Am Acad Dermatol (2014) 70:621-9. doi: 10.1016/j.jaad.2014.01.857

82. Euvrard S, Kanitakis J, Claudy A. Skin Cancers After Organ Transplantation - Reply. N Engl J Med (2003) 349:613-4. doi: 10.1056/NEJM20030 8073490618

83. Wilkins K, Turner R, Dolev JC, LeBoit PE, Berger TG, Maurer TA. Cutaneous Malignancy and Human Immunodeficiency Virus Disease. J Am Acad Dermatol (2006) 54:189-206. doi: 10.1016/j.jaad.2004. 11.060

84. Crum-Cianflone N, Hullsiek KH, Satter E, Marconi V, Weintrob A, Ganesan A, et al. Cutaneous Malignancies Among HIV-Infected Persons. Arch Intern Med (2009) 169:1130-8. doi: 10.1001/archinternmed.2009.104

85. Grulich AE, van Leeuwen MT, Falster MO, Vajdic CM. Incidence of Cancers in People With HIV/AIDS Compared With Immunosuppressed Transplant Recipients: A Meta-Analysis. Lancet (2007) 370:59-67. doi: 10.1016/S01406736(07)61050-2

86. Asgari MM, Ray GT, Quesenberry CP, Katz KA, Silverberg MJ. Association of Multiple Primary Skin Cancers With Human Immunodeficiency Virus Infection, CD4 Count, and Viral Load. JAMA Dermatol (2017) 153:892-6. doi: 10.1001/jamadermatol.2017.1716

87. Coates SJ, Leslie KS. What's New in HIV Dermatology? F1000Res (2019) 8: F1000. doi: 10.12688/f1000research.16182.1

88. Stulberg DL, Crandell B, Fawcett RS. Diagnosis and Treatment of Basal Cell and Squamous Cell Carcinomas. Am Fam Phys (2004) 70:1481-8. 
89. Netscher DT, Leong M, Orengo I, Yang D, Berg C, Krishnan B. Cutaneous Malignancies: Melanoma and Nonmelanoma Types. Plast Reconstruct Surg (2011) 127:37e-56e. doi: 10.1097/PRS.0b013e318206352b

90. Toll A, Margalef P, Masferrer E, Ferrándiz-Pulido C, Gimeno J, Pujol RM, et al. Active Nuclear IKK Correlates With Metastatic Risk in Cutaneous Squamous Cell Carcinoma. Arch Dermatol Res (2015) 307:721-9. doi: 10.1007/s00403-015-1579-6

91. Wilkins K, Dolev JC, Turner R, LeBoit PE, Berger TG, Maurer TA. Approach to the Treatment of Cutaneous Malignancy in HIV-Infected Patients. Dermatol Ther (2005) 18:77-86. doi: 10.1111/j.1529-8019.2005.05003.x

92. Nguyen P, Vin-Christian K, Ming ME, Berger T. Aggressive Squamous Cell Carcinomas in Persons Infected With the Human Immunodeficiency Virus. Arch Dermatol (2002) 138:758-63. doi: 10.1001/archderm.138.6.758

93. Otley CC. Immunosuppression and Skin Cancer - Pathogenetic Insights, Therapeutic Challenges, and Opportunities for Innovation. Arch Dermatol (2002) 138:827-8. doi: 10.1001/archderm.138.6.827

94. Neves-Motta R, De Almeida Ferry FR, Basílio-De-Oliveira CA, De Souza Carvalho R, Martins CJ, Eyer-Silva WA, et al. Highly Aggressive Squamous Cell Carcinoma in an HIV-Infected Patient. Rev Soc Bras Med Trop (2004) 37:496-8. doi: 10.1590/S0037-86822004000600013

95. Olson AL, Gaffney CA, Starr P, Dietrich AJ. The Impact of an AppearanceBased Educational Intervention on Adolescent Intention to Use Sunscreen. Health Educ Res (2008) 23:763-9. doi: 10.1093/her/cym005

96. Reusser NM, Downing C, Guidry J, Tyring SK. HPV Carcinomas in Immunocompromised Patients. J Clin Med (2015) 4:260-81. doi: 10.3390/ jcm4020260

97. Alam M, Armstrong A, Baum C, Bordeaux JS, Brown M, Busam KJ, et al. Guidelines of Care for the Management of Cutaneous Squamous Cell Carcinoma. J Am Acad Dermatol (2018) 78:560-78. doi: 10.1016/j.jaad.2017.10.007

98. Bejar C, Basset-Seguin N, Faure F, Fieschi C, Frances C, Guenne C, et al. French ENT Society (SFORL) Guidelines for the Management of Immunodeficient Patients With Head and Neck Cancer of Cutaneous Origin. Eur Ann Otorhinolaryngol Head Neck Dis (2014) 131:121-9. doi: 10.1016/j.anorl.2014.02.002

99. Deeken JF, Tjen-A-Looi A, Rudek MA, Okuliar C, Young M, Little RF, et al. The Rising Challenge of Non-AIDS-Defining Cancers in HIV-Infected Patients. Clin Infect Dis (2012) 55:1228-35. doi: 10.1093/cid/cis613

100. Blazy A, Hennequin C, Gornet J-M, Furco A, Gérard L, Lémann M, et al. Anal Carcinomas in HIV-Positive Patients: High-Dose Chemoradiotherapy Is Feasible in the Era of Highly Active Antiretroviral Therapy. Dis Colon Rectum (2005) 48:1176-81. doi: 10.1007/s10350-004-0910-7

101. Biggar RJ, Kirby KA, Atkinson T, McNeel TS, Engels E, Grp ACMS. Cancer Risk in Elderly Persons With HIV/AIDS. JAIDS J Acquir Immune Defic Syndr (2004) 36:861-8. doi: 10.1097/00126334-200407010-00014

102. Hofbauer GF, Anliker M, Arnold A, Binet I, Hunger R, Kempf W, et al. Swiss Clinical Practice Guidelines for Skin Cancer in Organ Transplant Recipients. Swiss Med Wkly (2009) 139(29-30):407-15. doi: 10.5167/uzh-25639

103. Euvrard S, Kanitakis J, Pouteilnoble C, Dureau G, Touraine J, Faure M, et al. Comparative Epidemiologic-Study of Premalignant and Malignant Epithelial Cutaneous Lesions Developing After Kidney and Heart-Transplantation. J Am Acad Dermatol (1995) 33:222-9. doi: 10.1016/0190-9622(95)90239-2

104. Hochman M, Lang P. Skin Cancer of the Head and Neck. Med Clin North Am (1999) 83:261-. doi: 10.1016/s0025-7125(05)70101-2

105. Trakatelli M, Morton C, Nagore E, Ulrich C, Del Marmol V, Peris K, et al. Update of the European Guidelines for Basal Cell Carcinoma Management. Eur J Dermatol (2014) 24(3):312-29. doi: 10.1684/ejd.2014.2271

106. Dandurand T, Petit P, Martel P, Guillot B. Management of Basal Cell Carcinoma in Adults Clinical Practice Guidelines. Eur J Dermatol (2006) 16(4):394-401.

107. Rowe DE. Comparison of Treatment Modalities for Basal Cell Carcinoma. Clin Dermatol (1995) 13:617-20. doi: 10.1016/0738-081x(95)00067-p

108. Stratigos AJ, Garbe C, Dessinioti C, Lebbe C, Bataille V, Bastholt L, et al. European Interdisciplinary Guideline on Invasive Squamous Cell Carcinoma of the Skin: Part 2. Treatment. Eur J Cancer (2020) 128:83-102. doi: 10.1016/ j.ejca.2020.01.008

109. Reschly MJ, Messina JL, Zaulyanov LL, Cruse W, Fenske NA. Utility of Sentinel Lymphadenectomy in the Management of Patients With High-Risk
Cutaneous Squamous Cell Carcinoma. Dermatol Surg (2003) 29:135-40. doi: 10.1046/j.1524-4725.2003.29035.x

110. Veness MJ, Morgan GJ, Palme CE, Gebski V. Surgery and Adjuvant Radiotherapy in Patients With Cutaneous Head and Neck Squamous Cell Carcinoma Metastatic to Lymph Nodes: Combined Treatment Should be Considered Best Practice. Laryngoscope (2005) 115:870-5. doi: 10.1097/ 01.MLG.0000158349.64337.ED

111. Likhacheva A, Awan M, Barker CA, Bhatnagar A, Bradfield L, Brady MS, et al. Definitive and Postoperative Radiation Therapy for Basal and Squamous Cell Cancers of the Skin: Executive Summary of an American Society for Radiation Oncology Clinical Practice Guideline. Pract Radiat Oncol (2020) 10:8-20. doi: 10.1016/j.prro.2019.10.014

112. Manyam BV, Garsa AA, Chin R-I, Reddy CA, Gastman B, Thorstad W, et al. A Multi-Institutional Comparison of Outcomes of Immunosuppressed and Immunocompetent Patients Treated With Surgery and Radiation Therapy for Cutaneous Squamous Cell Carcinoma of the Head and Neck. Cancer (2017) 123:2054-60. doi: 10.1002/cncr.30601

113. Babington S, Veness MJ, Cakir B, Gebski VJ, Morgan GJ. Squamous Cell Carcinoma of the Lip: Is There a Role for Adjuvant Radiotherapy in Improving Local Control Following Incomplete or Inadequate Excision? ANZ J Surg (2003) 73:621-5. doi: 10.1046/j.1445-2197.2003.t01-102710.x

114. Porceddu SV, Bressel M, Poulsen MG, Stoneley A, Veness MJ, Kenny LM, et al. Postoperative Concurrent Chemoradiotherapy Versus Postoperative Radiotherapy in High-Risk Cutaneous Squamous Cell Carcinoma of the Head and Neck: The Randomized Phase III TROG 05.01 Trial. J Clin Oncol (2018) 36:1275-83. doi: 10.1200/JCO.2017.77.0941

115. Grossi Marconi D, da Costa Resende B, Rauber E, de Cassia Soares P, Fernandes JM, Mehta N, et al. Head and Neck Non-Melanoma Skin Cancer Treated By Superficial X-Ray Therapy: An Analysis of 1021 Cases. PloS One (2016) 11:e0156544. doi: 10.1371/journal.pone.0156544

116. Mallon E, Dawber R. Cryosurgery in the Treatment of Basal Cell Carcinoma - Assessment of One and Two Freeze-Thaw Cycle Schedules. Dermatol Surg (1996) 22:854-8. doi: 10.1111/j.1524-4725.1996.tb00588.x

117. Miller SJ. The National Comprehensive Cancer Network (NCCN) Guidelines of Care for Nonmelanoma Skin Cancers. Dermatol Surg (2000) 26:289-92. doi: 10.1111/j.1524-4725.2000.00005.x

118. Amaral T, Garbe C. Non-Melanoma Skin Cancer: New and Future Synthetic Drug Treatments. Expert Opin Pharmacother (2017) 18:689-99. doi: 10.1080/14656566.2017.1316372

119. Cheraghi N, Cognetta AJ, Goldberg D. Radiation Therapy in Dermatology: Non-Melanoma Skin Cancer. J Drugs Dermatol (2017) 16:464-9.

120. Carneiro B, Watkin W, Mehta U, Brockstein B. Metastatic Basal Cell Carcinoma: Complete Response to Chemotherapy and Associated Pure Red Cell Aplasia. Cancer Invest (2006) 24:396-400. doi: 10.1080/ 07357900600705474

121. Zelin E, Zalaudek I, Agozzino M, Dianzani C, Dri A, Di Meo N, et al. Neoadjuvant Therapy for Non-Melanoma Skin Cancer: Updated Therapeutic Approaches for Basal, Squamous, and Merkel Cell Carcinoma. Curr Treat Options Oncol (2021) 22:35. doi: 10.1007/s11864-021-00826-3

122. Yanik EL, Pfeiffer RM, Freedman DM, Weinstock MA, Cahoon EK, Arron ST, et al. Spectrum of Immune-Related Conditions Associated With Risk of Keratinocyte Cancers Among Elderly Adults in the United States. Cancer Epidemiol Biomarkers Prev (2017) 26:998-1007. doi: 10.1158/10559965.EPI-17-0003

123. Hall ET, Fernandez-Lopez E, Silk AW, Dummer R, Bhatia S. Immunologic Characteristics of Nonmelanoma Skin Cancers: Implications for Immunotherapy. Am Soc Clin Oncol Educ Book (2020) 40:1-10. doi: 10.1200/EDBK_278953

124. Migden MR, Rischin D, Schmults CD, Guminski A, Hauschild A, Lewis KD, et al. PD-1 Blockade With Cemiplimab in Advanced Cutaneous SquamousCell Carcinoma. N Engl J Med (2018) 379:341-51. doi: 10.1056/ NEJMoa1805131

125. Falchook GS, Leidner R, Stankevich E, Piening B, Bifulco C, Lowy I, et al. Responses of Metastatic Basal Cell and Cutaneous Squamous Cell Carcinomas to Anti-PD1 Monoclonal Antibody REGN2810. J Immunother Cancer (2016) 4:70. doi: 10.1186/s40425-016-0176-3 
126. Chang ALS, Tran DC, Cannon JGD, Li S, Jeng M, Patel R, et al. Pembrolizumab for Advanced Basal Cell Carcinoma: An InvestigatorInitiated, Proof-of-Concept Study. J Am Acad Dermatol (2019) 80:564-6. doi: 10.1016/j.jaad.2018.08.017

127. Mohan SV, Kuo KY, Chang ALS. Incidental Regression of an Advanced Basal Cell Carcinoma After Ipilimumab Exposure for Metastatic Melanoma. JAAD Case Rep (2016) 2:13-5. doi: 10.1016/j.jdcr.2015.11.007

128. Dummer R, Ascierto PA, Basset-Seguin N, Dréno B, Garbe C, Gutzmer R, et al. Sonidegib and Vismodegib in the Treatment of Patients With Locally Advanced Basal Cell Carcinoma: A Joint Expert Opinion. J Eur Acad Dermatol Venereol (2020) 34:1944-56. doi: 10.1111/jdv.16230

129. Hoffmann V, Husak R, Maiwirth F, Sasama B, Zahn A, Guski S, et al. Sonidegib in a Patient With Multiple Basal Cell Carcinomas and HIV Infection. J Dtsch Dermatol Ges (2021) 19(4):592-4. doi: 10.1111/ddg.14355

130. Peng L, Wang Y, Hong Y, Ye X, Shi P, Zhang J, et al. Incidence and Relative Risk of Cutaneous Squamous Cell Carcinoma With Single-Agent BRAF Inhibitor and Dual BRAF/MEK Inhibitors in Cancer Patients: A Meta-Analysis. Oncotarget (2017) 8:83280-91. doi: 10.18632/ oncotarget.21059

131. Sekulic A, Migden MR, Oro AE, Dirix L, Lewis KD, Hainsworth JD, et al. Efficacy and Safety of Vismodegib in Advanced Basal-Cell Carcinoma. N Engl J Med (2012) 366:2171-9. doi: 10.1056/NEJMoa1113713

132. Scalvenzi M, Villani A, Mazzella C, Cappello M, Salvatores GDF, Costa C. Vismodegib Treatment in a HIV Positive Patient on Antiretroviral Therapy. Indian J Dermatol Venereol Leprol (2018) 84:758-60. doi: 10.4103/ijdvl. IJDVL_92_18

133. Tran AQ, Patete CL, Blessing NW, Rong AJ, Garcia AL, Dubovy S, et al. Orbito-Scleral-Sinus Invasion of Basal Cell Carcinoma in an Immunocompromised Patient on Vismodegib. Orbit (2021) 40:155-8. doi: 10.1080/01676830.2020.1753783

134. Berretta M, Caraglia M, Martellotta F, Zappavigna S, Lombardi A, Fierro C, et al. Drug-Drug Interactions Based on Pharmacogenetic Profile between Highly Active Antiretroviral Therapy and Antiblastic Chemotherapy in Cancer Patients with HIV Infection. Front Pharmacol (2016) 7:71. doi: 10.3389/fphar.2016.00071

135. Venanzi Rullo E, Ceccarelli M, Condorelli F, Facciolà A, Visalli G, D’Aleo F, et al. Investigational Drugs in HIV: Pros and Cons of Entry and Fusion Inhibitors (Review). Mol Med Rep (2019) 19(3):1987-95. doi: 10.3892/ mmr.2019.9840
136. Pinzone MR, Ceccarelli M, Venanzi Rullo E, Maresca M, Bruno R, Condorelli F, et al. Circulating Angiopoietin-Like Protein 2 Levels Are Associated With Decreased Renal Function in HIV+ Subjects on cART: A Potential Marker of Kidney Disease. BioMed Rep (2019) 10:140-4. doi: 10.3892/br.2019.1183

137. Cullen R, Hasbún P, Campos-Villenas M. Carcinoma Basocelular Superficial. Med Clin (2017) 149:140. doi: 10.1016/j.medcli.2016.10.017

138. Apalla Z, Calzavara-Pinton P, Lallas A, Argenziano G, Kyrgidis A, Crotti S, et al. Histopathological Study of Perilesional Skin in Patients Diagnosed With Nonmelanoma Skin Cancer. Clin Exp Dermatol (2016) 41:21-5. doi: $10.1111 /$ ced.12713

139. Zhao H, Shu G, Wang S. The Risk of Non-Melanoma Skin Cancer in HIVInfected Patients: New Data and Meta-Analysis. Int J STD AIDS (2016) 27:568-75. doi: 10.1177/0956462415586316

140. Garlassi E, Harding V, Weir J, Francis N, Nelson M, Newsom-Davis T, et al. Nonmelanoma Skin Cancers Among HIV-Infected Persons in the HAART Era. J Acquir Immune Defic Syndr (2012) 60:e63-5. doi: 10.1097/ QAI.0b013e318251b004

141. Berretta M, Lleshi A, Zanet E, Bearz A, Simonelli C, Fisichella R, et al. Bevacizumab Plus Irinotecan-, Fluorouracil-, and Leucovorin-Based Chemotherapy With Concomitant HAART in an HIV-Positive Patient With Metastatic Colorectal Cancer. Onkologie (2008) 31:394-7. doi: 10.1159/000132360

Conflict of Interest: The authors declare that the research was conducted in the absence of any commercial or financial relationships that could be construed as a potential conflict of interest.

Publisher's Note: All claims expressed in this article are solely those of the authors and do not necessarily represent those of their affiliated organizations, or those of the publisher, the editors and the reviewers. Any product that may be evaluated in this article, or claim that may be made by its manufacturer, is not guaranteed or endorsed by the publisher.

Copyright (c) 2021 Venanzi Rullo, Maimone, Fiorica, Ceccarelli, Guarneri, Berretta and Nunnari. This is an open-access article distributed under the terms of the Creative Commons Attribution License (CC BY). The use, distribution or reproduction in other forums is permitted, provided the original author(s) and the copyright owner(s) are credited and that the original publication in this journal is cited, in accordance with accepted academic practice. No use, distribution or reproduction is permitted which does not comply with these terms. 